\title{
Stabilization of a triplet diradical on a binuclear palladium(II) dipyrrin- dione
}

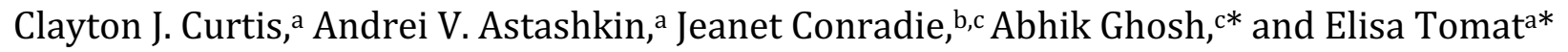 \\ a Department of Chemistry and Biochemistry, The University of Arizona, 1306 E. University Blvd., Tucson AZ 85721, \\ USA
}

b Department of Chemistry, University of the Free State, P.O. Box 339, Bloemfontein 9300, Republic of South Africa.

c Department of Chemistry, UiT - The Arctic University of Norway, N-9037 Tromsø, Norway

KEYWORDS: redox-active ligand, ligand-centered radical, dipyrrin-1,9-dione, oligopyrrole, triplet diradical

\begin{abstract}
Porphyrins and other macrocyclic oligopyrroles form a versatile class of redox-active ligands and electron reservoirs. The stabilization of unpaired electrons within oligopyrrolic $\pi$ systems adds to the available reactivity pathways and spin states of metal complexes for applications in catalysis and functional materials. In this context, bidentate dipyrrindiones are emerging as compact platforms for one-electron redox chemistry in transition metal complexes. We report the synthesis of a bis(aqua) palladium(II) dipyrrindione complex and its deprotonation-driven dimerization to form a hydroxobridged dinuclear complex. Electrochemical, spectroelectrochemical, and computational analyses indicate the accessibility of two reduction processes on the dipyrrindione frameworks of the dinuclear complex. The product of a two-electron reduction by cobaltocene was isolated and characterized. In the solid state, this cobaltocenium salt features a folded dianionic complex maintaining the hydroxo bridges between the divalent palladium centers. X-band and Q-band EPR spectroscopic experiments and DFT computational analysis allow assignment of the dianionic species as a triplet diradical supported by the dipyrrindione ligands. These dipyrroles, which are also known as propentdyopents and were initially isolated as urinary pigments and heme metabolites, extend the rich chemistry of bidentate dipyrrin ligands to include the stabilization of ligand-centered radicals.
\end{abstract}

\section{INTRODUCTION}

Coordination compounds of redox-active ligands, in which oxidizing and/or reducing equivalents can be stored on the ligand $\pi$ system, have generated broad interest owing to their potential applications in areas ranging from homogeneous catalysis ${ }^{1,2}$ to molecular magnetism ${ }^{3}$ to photovoltaic devices. ${ }^{4}$ The ability to host multiple spin centers on organic ligands is also central to applications in quantum information processing (e.g., spin qubits). ${ }^{5,6}$ Macrocyclic tetrapyrroles, such as porphyrins and corroles, are wellstudied examples of redox-active ligands, and their ability to host unpaired spins has been investigated extensively in both biological ${ }^{7}$ and synthetic ${ }^{8-13}$ systems. Several porphyrinoids ${ }^{14,15}$ and expanded porphyrin macrocycles ${ }^{16-19}$ also stabilize unpaired $\pi$ electrons. Besides macrocyclic structures, ${ }^{20,21}$ early examples of linear oligopyrrolic radicals in metal complexes were found within the study of bilindiones (Chart 1, a), 22-24 but more recent reports highlighted the formation of stable ligand-based radicals in metal complexes of tetradentate bis(phenolate)-dipyrrins (Chart $1, \mathrm{~b}),{ }^{25-29}$ bis(2-aminophenyl)-dipyrrins, ${ }^{30}$ and diimino- dipyrrins, ${ }^{31}$ as well as tridentate tripyrrindione (Chart 1 , c) ${ }^{20,32-35}$ and dihydrazonopyrrole ${ }^{36,37}$ scaffolds.

Chart 1. Metal complexes of linear pyrrolic ligands featuring ligand-based radicals
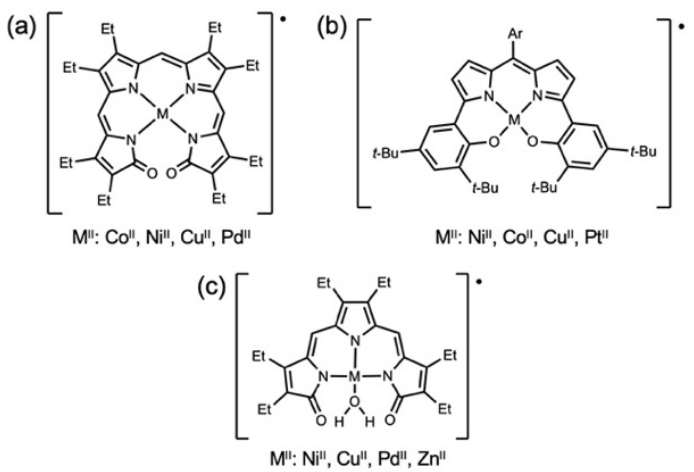

Contracting the conjugated $\pi$ system from tetradentate to tridentate to bidentate oligopyrroles, the stabilization of radicals becomes less common. Bidentate dipyrrin ligands coordinate a variety of metal ions ${ }^{38}$ and have been employed in multiple applications including metal-organic 
frameworks, ${ }^{39-41}$ catalysts, ${ }^{42,43}$ BODIPY fluorophores, ${ }^{44-46}$ and photovoltaics. ${ }^{47,48}$ Ligand-centered redox chemistry is observed in several dipyrrin complexes ${ }^{38}$ with varying stability depending on substitution; ${ }^{49}$ however, the bidentate dipyrrin system has not been generally employed for the stabilization of unpaired electrons. In contrast, the dipyrrin-1,9-dione motif serves as a compact dipyrrolic platform to host ligand-centered radicals. ${ }^{50-52}$ This bidentate ligand could therefore extend the diverse applications of dipyrrin complexes to include one-electron redox chemistry and a variety of spin states.

Historically referred to as propentdyopents, the naturally occurring dipyrrindione pigments result from the oxidative metabolism of heme $\mathrm{e}^{53,54}$ and were initially discovered within the urinary pigments collected from hyperbilirubinemia patients. ${ }^{55}$ The first dipyrrindione complexes were isolated from the degradation of bilindione complexes; ${ }^{23,56}$ however, we recently employed the $\mathrm{Hpdp} \bullet \mathrm{MeOH}$ adduct for the preparation of homoleptic ${ }^{50}$ and heteroleptic ${ }^{51,52}$ compounds (Chart 2). Because of the availability of lowlying $\pi^{*}$ molecular orbitals, these complexes typically undergo one-electron reduction processes localized on the dipyrrolic ligand framework. For instance, the fluorescence emission of BODIPY analog (pdp)BF $\mathrm{BF}_{2}$ (Chart 2b) can be quenched through reduction of the dipyrrindione platform to form a ligand-based radical. In addition, spectroelectrochemical and electron paramagnetic resonance (EPR) measurements showed that two sequential one-electron reductions of $\mathrm{Zn}(\mathrm{pdp})_{2}$ (Chart 2c) lead to a triplet diradical complex, which was detected in solution. ${ }^{50}$

Chart 2. Tetraethyl propentdyopent-methanol adduct (a) and reported complexes (b-d) (a)

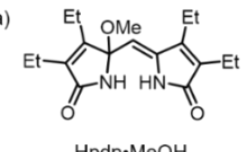

$\mathrm{Hpdp} \cdot \mathrm{MeOH}$

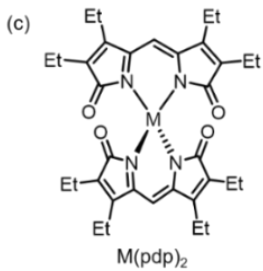

M: Co", Ni", Cu", Zn
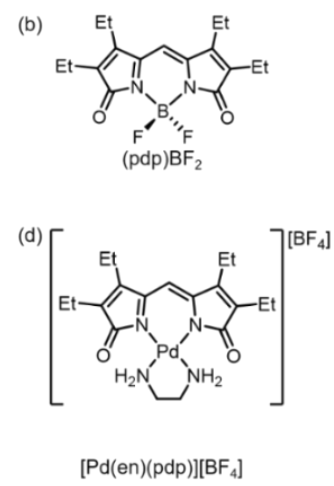

Diradical metal complexes featuring two ligand-based unpaired spins coordinated to diamagnetic metal centers (e.g., $\mathrm{d}^{8}$ or $\mathrm{d}^{10}$ ions) are observed in either the singlet or triplet state. ${ }^{57}$ In systems where the two ligands are coplanar, as in square planar complexes of aminophenols, ${ }^{58-60}$ phenylenediamines, ${ }^{61,62}$ and isothiosemicarbazides, ${ }^{63}$ antiferromagnetic coupling of the ligand-based radicals often results in the singlet state. The spin state can be altered by the introduction of a paramagnetic metal center resulting in coupling to the organic radicals, ${ }^{64}$ or by significant departures from coplanarity as in tetrahedral ${ }^{63,65}$ or octahedral ${ }^{66}$ homoleptic complexes that can afford triplet diradicals due to a ferromagnetic exchange interaction of the ligand-based $\pi$-radicals. Reports documenting diradicals in bridged dinuclear complexes featuring one redox-active ligand per metal center are rather scarce, but they point at an additional pathway for tuning spin exchange interac- tions between redox-active centers through modification of the bridged ligand. ${ }^{67,68}$

In this context, we sought to investigate the ability of the dipyrrindione framework to host unpaired spins in a bridged dinuclear system. In our previous investigations of the palladium(II) dipyrrindione complexes featuring primary amine ligands (e.g., $[\operatorname{Pd}(\mathrm{en})(\mathrm{pdp})]^{+}$, Chart $\left.2 \mathrm{~d}\right),{ }^{52}$ we found that the intramolecular hydrogen bonds are important for complex stability. This observation prompted us to explore the synthesis of a similar diaqua complex. Given the acidity of palladium-bound aqua ligands, 69 we envisioned that such a complex would serve as a precursor to a bridged $\mu$-hydroxo dimer, in turn allowing access to a dipyrrindione diradical species upon reduction.

\section{RESULTS AND DISCUSSION}

\section{Synthesis and chemical characterization}

The tetraethyl dipyrrindione ligand was synthesized using previously reported methods ${ }^{50,70}$ as a methanol adduct (Hpdp•MeOH, Chart 2a) and added to a dichloromethane solution of palladium(II) acetylacetonate. In these conditions, acidification of the reaction mixture was expected to facilitate the dissociation of the bidentate acac- ligands and their replacement with a higher-affinity ligand.71,72 Indeed, the addition of aqueous $\mathrm{HBF}_{4}$ resulted in a color change from yellow to deep red over the course of 3-4 hours at room temperature. Furthermore, this particular acid was chosen so as to include the non-coordinating counterion $\mathrm{BF}_{4}{ }^{-}$and facilitate crystallization. Monitoring the reaction progress via optical absorption spectroscopy, we observed the gradual decrease of the single absorption band of $\mathrm{Hpdp} \bullet \mathrm{MeOH}$ at $280 \mathrm{~nm}$ accompanied by the growth of two main bands at 382 and $545 \mathrm{~nm}$, consistent with our previous reports on dipyrrindione complexes. ${ }^{50,52}$

In the course of our synthetic manipulations, we observed that exposing a dichloromethane solution of this red complex to an aqueous wash resulted in an immediate color change of the organic phase from red to blue. The absorption spectrum of the blue solution in $\mathrm{CH}_{2} \mathrm{Cl}_{2}$ presents a shift in the main bands to 372 and $585 \mathrm{~nm}$ (Figure 1 , Table S1), clearly indicating the formation of a different species.

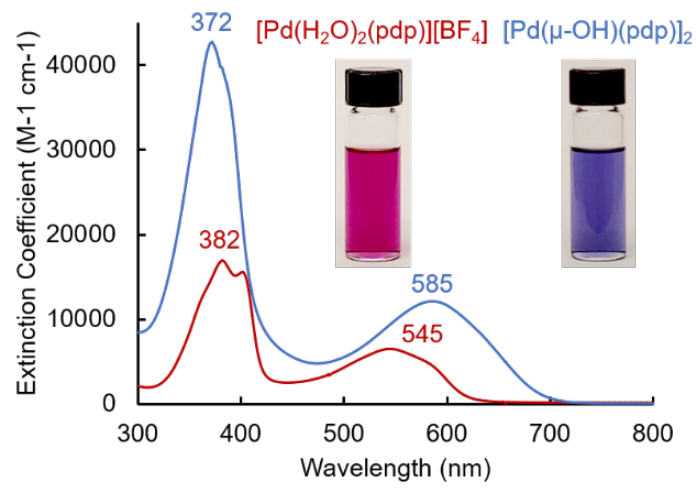

Figure 1. UV-visible absorption spectra of $\left[\mathrm{Pd}\left(\mathrm{H}_{2} \mathrm{O}\right)_{2}(\mathrm{pdp})\right]\left[\mathrm{BF}_{4}\right]$ (red) and $[\mathrm{Pd}(\mu-\mathrm{OH})(\mathrm{pdp})]_{2}$ (blue) in $\mathrm{CH}_{2} \mathrm{Cl}_{2}$.

The isolated red and blue complexes are diamagnetic, as determined by ${ }^{1} \mathrm{H}$ and ${ }^{13} \mathrm{C}$ NMR spectroscopy. The ${ }^{1} \mathrm{H}$ NMR 
spectrum of the red complex (Figure S1) features pdpresonances analogous to those in our previous reports. ${ }^{52}$ The corresponding ${ }^{13} \mathrm{C}$ NMR spectrum (Figure S2) only featured resonances attributed to the dipyrrindione framework, eliminating the possibility of a bound acac ion. In addition, a sharp singlet integrating to four protons at $6.66 \mathrm{ppm}$ in the ${ }^{1} \mathrm{H}$ NMR spectrum suggested the presence of two coordinated aqua ligands bound to the metal center.

In the ${ }^{1} \mathrm{H}$ and ${ }^{13} \mathrm{C}$ NMR spectra of the blue complex (Figures S1, S2), the resonances corresponding to the ligand framework were shifted slightly upfield relative to the red complex (e.g., 5.55 ppm vs. 5.87 ppm for the meso-type proton). The most notable difference between the spectra was the disappearance of the $4 \mathrm{H}$ singlet at $6.66 \mathrm{ppm}$ and the appearance of a new singlet at $3.07 \mathrm{ppm}$, which integrated to one proton relative to the meso-type resonance. Because of the increased acidity of palladium-bound aqua ligands, ${ }^{73}$ we hypothesized a deprotonation and formation of a hydroxo-bridged species as previously observed in the case of diaqua palladium(II)-BINAP complexes, which readily formed hydroxo dimers upon treatment with $4 \AA$ molecular sieves in acetone. ${ }^{74}$ Conclusive data on the structure of both complexes in the solid state were then obtained by X-ray crystallography (see Table S2 for collection parameters).

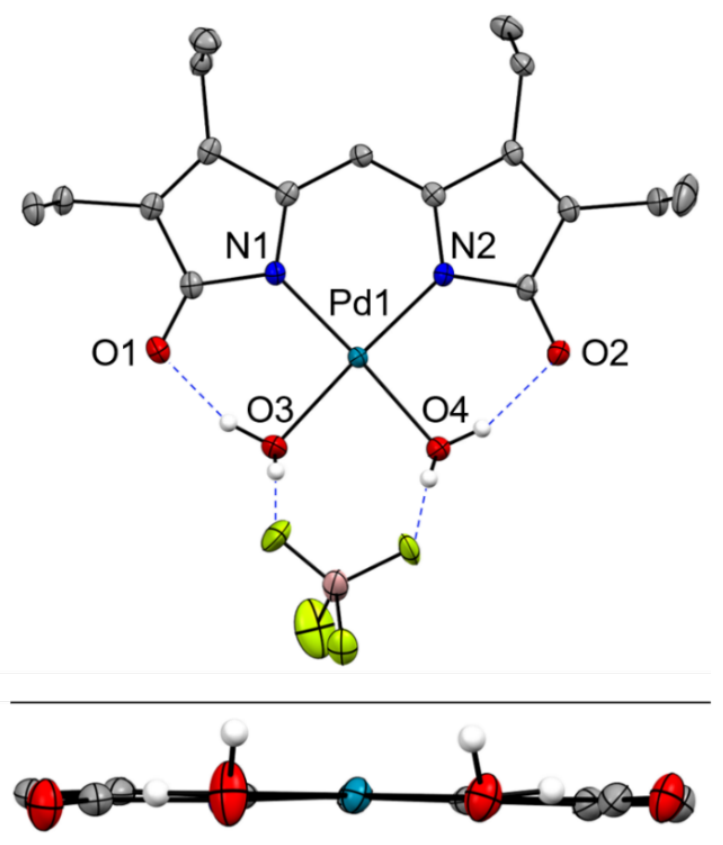

Figure 2. Crystal structure of $\left[\mathrm{Pd}\left(\mathrm{H}_{2} \mathrm{O}\right)_{2}(\mathrm{pdp})\right]\left[\mathrm{BF}_{4}\right]$ showing a partial labeling scheme. Carbon-bound hydrogen atoms are omitted for clarity. Non-hydrogen atoms are displayed as thermal displacement ellipsoids set at the $50 \%$ probability level. In the side view (bottom panel), ethyl substituents were removed for clarity. CCDC: 2077676.

The crystal structure of the red complex confirmed the coordination of the $\mathrm{pdp}^{-}$ligand to a single palladium(II) center also featuring two aqua ligands and a tetrafluoroborate counter anion in close vicinity (Figures 2 and S3). The coordination geometry of the palladium(II) center is square planar, and the $\mathrm{Pd}-\mathrm{N} / \mathrm{O}$ bond distances (ranging from $1.984(3)$ to $2.060(3) \AA$ ) and angles (84.3-92.6 ${ }^{\circ}$ ) are consistent with those in analogous palladium(II) dipyrrinato complexes ${ }^{75-78}$ and heteroleptic dipyrrindione palladium(II) structures. ${ }^{52}$ The $\mathrm{pdp}^{-}$ligand is fully coplanar with the palladium(II) coordination plane, and the bond lengths in the dipyrrindione framework (Table S3) indicate two terminal carbonyl groups on the pyrrolic $\alpha$ positions (C-0, 1.223(3) and $1.226(3) \AA)$. As previously reported for dipyrrindione ${ }^{52}$ and tripyrrindione $\mathrm{e}^{32,33,35}$ complexes, these carbonyl groups serve as effective hydrogen-bonding acceptors: the aqua ligands are engaged in hydrogen-bonding interactions with both the propentdyopent scaffold and the tetrafluoroborate anions, and all aqua hydrogens were located on the Fourier map during structure refinement.
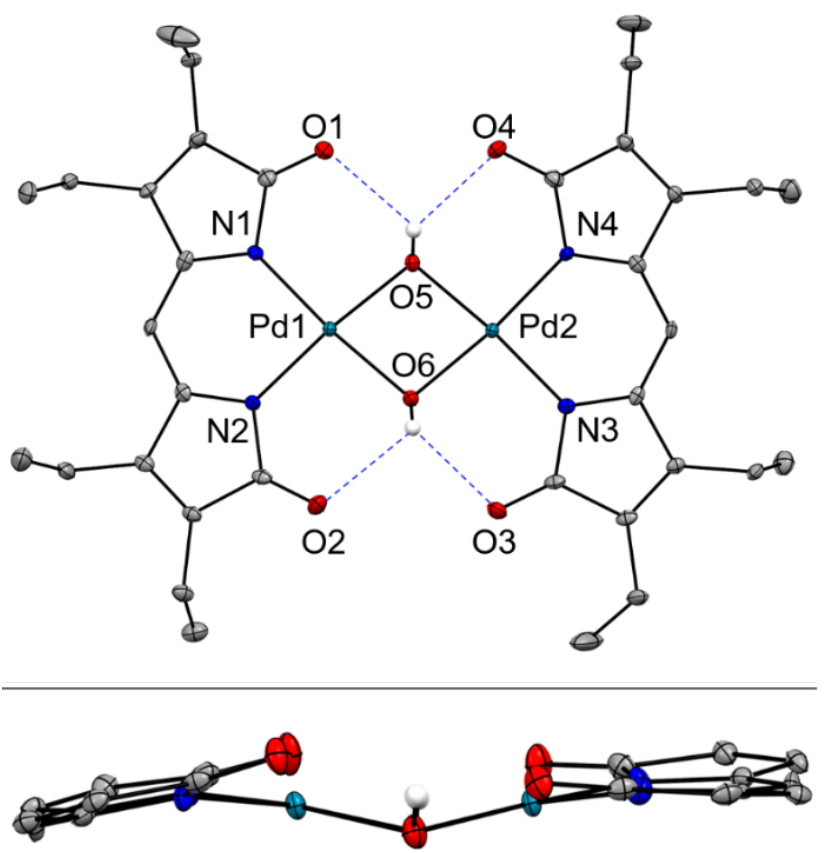

Figure 3. Crystal structure of $[\mathrm{Pd}(\mu-\mathrm{OH})(\mathrm{pdp})]_{2}$ showing a partial labeling scheme. Carbon-bound hydrogen atoms are omitted for clarity. Non-hydrogen atoms are displayed as thermal displacement ellipsoids set at the $50 \%$ probability level. In the side view (bottom panel), ethyl substituents were removed for clarity. CCDC: 2077677.

The crystal structure of the blue complex (Figures 3 and S4) presents a coordination dimer, wherein the two palladium(II) centers are each bound to one dipyrrindione and two bridging hydroxo ligands. In contrast to the red complex $\left[\mathrm{Pd}\left(\mathrm{H}_{2} \mathrm{O}\right)_{2}(\mathrm{pdp})\right]^{+}$, the blue species $[\mathrm{Pd}(\mu-\mathrm{OH})(\mathrm{pdp})]_{2}$ is neutral, and the two $\mathrm{pdp}^{-}$ligands are slightly canted with a minor curvature of the rigid dipyrrolic scaffold. The Pd-N/O bond distances (1.979(3)-2.014(3) Å) are similar to those in $\left[\mathrm{Pd}\left(\mathrm{H}_{2} \mathrm{O}\right)_{2}(\mathrm{pdp})\right]\left[\mathrm{BF}_{4}\right]$, and the bond lengths in the dipyrrolic framework remain largely unchanged upon dimerization (Table S4), indicating no change in the redox state of either the palladium(II) center or the ligand scaffold. The hydrogen atoms of the $\mu$-hydroxo ligands are engaged in hydrogen-bonding interactions with two carbonyl oxygen atoms of the dipyrrindione ligands (Figure 3).

The solid-state analysis of $\left[\mathrm{Pd}\left(\mathrm{H}_{2} \mathrm{O}\right)_{2}(\mathrm{pdp})\right]\left[\mathrm{BF}_{4}\right]$ and $[\mathrm{Pd}(\mu-\mathrm{OH})(\mathrm{pdp})]_{2}$ is consistent with the observed differences between their respective ${ }^{1} \mathrm{H}$ NMR spectra in $\mathrm{CDCl}_{3}$ solutions: the bound aqua ligands in the $\left[\mathrm{Pd}\left(\mathrm{H}_{2} \mathrm{O}\right)_{2}(\mathrm{pdp})\right]^{+}$ 
complex (i.e., $4 \mathrm{H}$ at $6.66 \mathrm{ppm}$ ) are deprotonated in aqueous conditions to form the dimeric complex $[\mathrm{Pd}(\mu-$ $\mathrm{OH})(\mathrm{pdp})]_{2}$ featuring two $\mu$-hydroxo bridges (i.e., $2 \mathrm{H}$ at $3.07 \mathrm{ppm}$ ). Although the chemical shift of hydroxo ligands bridging two palladium(II) centers is typically further upfield (-0.28 to $-3.0 \mathrm{ppm}),{ }^{79-82}$ we attribute the comparatively downfield resonance of our dimeric complex to the hydrogen-bonding interactions observed in the crystallographic data and likely effective in solution as well.

The interconversion between $\left[\mathrm{Pd}\left(\mathrm{H}_{2} \mathrm{O}\right)_{2}(\mathrm{pdp})\right]\left[\mathrm{BF}_{4}\right]$ and the bis- $\mu$-hydroxo dimer $[\mathrm{Pd}(\mu-\mathrm{OH})(\mathrm{pdp})]_{2}$ (Scheme 1) could be monitored by optical absorption spectroscopy in organic solvents. When starting with a solution of $\left[\mathrm{Pd}\left(\mathrm{H}_{2} \mathrm{O}\right)_{2}(\mathrm{pdp})\right]\left[\mathrm{BF}_{4}\right]\left(75 \mu \mathrm{M}, \mathrm{CH}_{2} \mathrm{Cl}_{2}\right)$, the addition of triethylamine resulted in the rapid consumption of the diaqua complex $\left(\lambda_{\max } 545 \mathrm{~nm}\right.$ ) and formation of the $\mu$-hydroxo dimer $\left(\lambda_{\max } 585 \mathrm{~nm}\right)$, with saturation reached at $\sim 2.0$ equiv of base (Figure S5). Conversely, the addition of trifluoroacetic acid (TFA, 2 equiv) to a solution of $[\mathrm{Pd}(\mu-\mathrm{OH})(\mathrm{pdp})]_{2}$ (51 $\left.\mu \mathrm{M}, 95: 5(\mathrm{v} / \mathrm{v}) \mathrm{CH}_{2} \mathrm{Cl}_{2}: \mathrm{CH}_{3} \mathrm{OH}\right)$ resulted in the rapid shift of the lower energy maximum from 585 to $545 \mathrm{~nm}$, confirming the formation of the diaqua monomer complex (Figure S5). The addition of a small amount of methanol to the solvent mixture (i.e., $5 \% \mathrm{CH}_{3} \mathrm{OH}$ in $\mathrm{CH}_{2} \mathrm{Cl}_{2}$ ) facilitated proton transfer in solution. Under these acidic conditions, however, partial demetallation was observed, particularly, upon addition of more than 2.0 equiv of acid.

\section{Scheme 1. Reversible deprotonation and dimerization of $\left[\mathrm{Pd}\left(\mathrm{H}_{2} \mathrm{O}\right)_{2}(\mathrm{pdp})\right]^{+}$.}

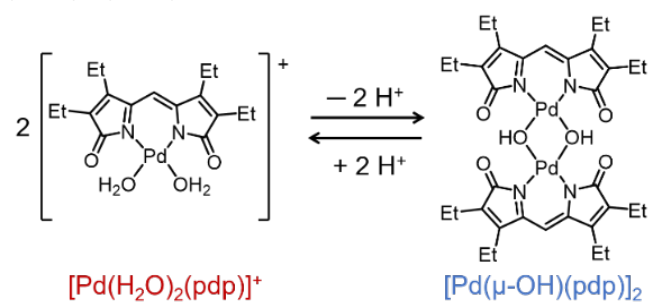

Overall, these experiments indicated the formation of a diaqua $\mathrm{Pd}(\mathrm{II})$ dipyrrindione complex that is similar to the analogous complexes of primary amines, ${ }^{52}$ in which the square planar coordination is stabilized by hydrogenbonding interactions between ligands. The metal-bound aqua ligands, however, are quite acidic and undergo facile deprotonation concurrently with the formation of a bis $(\mu-$ $\mathrm{OH})$ dimeric complex. A pronounced color change of the solution from red to blue accompanies the conversion of the diaqua complex to the bis-hydroxo species through deprotonation and dimerization.

\section{DFT analysis of $\left[\mathrm{Pd}\left(\mathrm{H}_{2} \mathrm{O}\right)_{2}(\mathrm{pdp})\right]^{+}$and $[\mathrm{Pd}(\mu-\mathrm{OH})(p d p)]_{2}$}

Density functional theory (DFT) calculations have an impressive track record in describing many electronicstructural aspects of porphyrins and related molecules. Some key problems addressed in one of our laboratories include the question of ligand noninnocence, ${ }^{83}$ metal versus ligand-centered oxidation and reduction, ${ }^{84,85}$ metalmetal bonding, 86 and aromaticity. ${ }^{87,88}$ Others have focused on the mechanisms of cytochrome $\mathrm{P} 450^{89}$ and other heme enzymes and on metalloporphyrin-mediated $\mathrm{CO}_{2}$ reduction, ${ }^{90}$ among other topics.
All-electron dispersion-corrected scalar-relativistic DFT (OLYP-D3) calculations with large STO-TZ2P basis sets were accordingly deployed to contextualize the experimental results on $\left[\mathrm{Pd}\left(\mathrm{H}_{2} \mathrm{O}\right)_{2}(\mathrm{pdp})\right]^{+}$and $[\mathrm{Pd}(\mu-\mathrm{OH})(\mathrm{pdp})]_{2}$. Although the optimized bond distances and angles were generally in good agreement with experimental values (Table S5), a folded conformation was found for the dinuclear complex (Figure S6), at odds with an essentially planar geometry in the solid state (Figure 3). The Pd-Pd distance $(2.685 \AA)$ in the folded conformation was shorter than the sum of the Van der Waals radii (3.26 $\AA$ ) indicating a potential bonding interaction. The MOs for this $C_{2 \mathrm{v}}$ geometry show filled bonding and antibonding orbitals involving the $\operatorname{Pd}\left(d_{\mathrm{z}}{ }^{2}\right)$ orbitals (Figure S7) typical of $d^{8}-d^{8}$ interactions, ${ }^{67,91}$ in which an overall weakly bonding character results from mixing with the metal $s$ and $p_{z}$ orbitals and is a potential driving force for this conformation. Although the occurrence of this folded structure in solution cannot be ruled out, packing effects in the crystalline solid are likely responsible for the rather planar structure observed in the solid state (Figure 3).
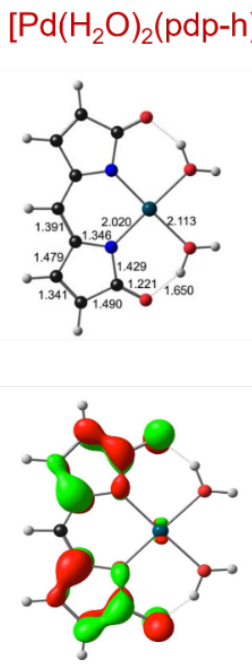

LUMO, $a_{2}$

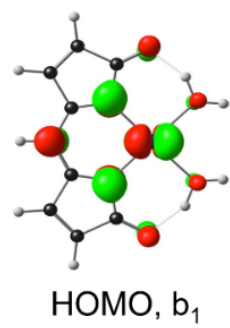

$[\mathrm{Pd}(\mu-\mathrm{OH})(\mathrm{pdp}-\mathrm{h})]_{2}$

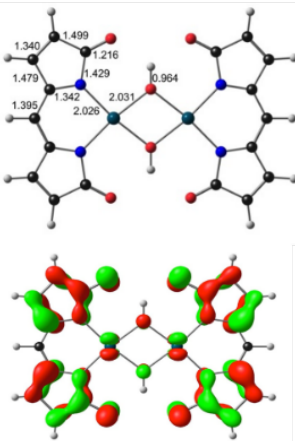

$\mathrm{LUMO}+1, \mathrm{~b}_{3 \mathrm{~g}}$

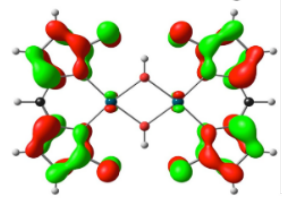

LUMO, $a_{u}$

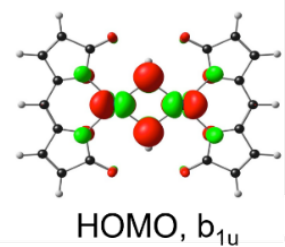

Figure 4. Frontier Kohn-Sham MOs of the simplified model complexes $\left[\mathrm{Pd}\left(\mathrm{H}_{2} \mathrm{O}\right)_{2}(\mathrm{pdp}-\mathrm{h})\right]^{+}\left(\mathrm{C}_{2 \mathrm{v}}\right)$ and $[\mathrm{Pd}(\mu-\mathrm{OH})(\mathrm{pdp}-\mathrm{h})]_{2}$ $\left(D_{2 \mathrm{~h}}\right)$ with selected bond lengths of optimized geometries $(\AA)$.

Since the folding of the dimer structure is likely to be soft mode with relatively little impact on intramolecular bonding, we chose to carry out further analysis with a symmetry-constrained $D_{2 h}$ (i.e., unfolded) model, $[\operatorname{Pd}(\mu-$ $\mathrm{OH})(\mathrm{pdp}-\mathrm{h})]_{2}$, with unsubstituted $\mathrm{pdp}^{-}$ligands. An examination of the HOMO and LUMO of the monomeric and dimeric complexes provided a plausible explanation for the 40-nm spectral redshift of the lowest-energy band in the UV-vis spectrum of the latter. Broadly speaking, the HOMOs of both the monomeric and dimeric complexes show 
substantial mixing of $\operatorname{Pd}(4 d)$ and $\operatorname{pdp}(\pi)$-based orbitals (Figures 4 and S8). The LUMOs, in contrast, are almost purely pdp-based. Compared to $\left[\mathrm{Pd}\left(\mathrm{H}_{2} \mathrm{O}\right)_{2}(\text { pdp-h) }]^{+}\right.$, the HOMO of $[\mathrm{Pd}(\mu-\mathrm{OH})(\mathrm{pdp}-\mathrm{h})]_{2}$ exhibits increased destabilizing filled-filled $\operatorname{Pd}\left(\mathrm{d}_{\pi}\right)-\mathrm{O}\left(\mathrm{p}_{\mathrm{z}}\right)$ antibonding interactions, which translates to a lower HOMO-LUMO gap and thus to the observed spectral redshift.

\section{Characterization of ligand-based reduction products}

The electrochemical profiles of $\left[\mathrm{Pd}\left(\mathrm{H}_{2} \mathrm{O}\right)_{2}(\mathrm{pdp})\right]\left[\mathrm{BF}_{4}\right]$ and $[\mathrm{Pd}(\mu-\mathrm{OH})(\mathrm{pdp})]_{2}$ were investigated by cyclic voltammetry in $\mathrm{CH}_{2} \mathrm{Cl}_{2}$, with potentials referenced to the ferrocenium/ferrocene redox couple $\left(\mathrm{Fc}^{+} / \mathrm{Fc}\right)$. The voltammogram of $\left[\mathrm{Pd}\left(\mathrm{H}_{2} \mathrm{O}\right)_{2}(\mathrm{pdp})\right]\left[\mathrm{BF}_{4}\right]$ displayed an irreversible reduction event at $-0.431 \mathrm{~V}$ (Figure 5, left panel) indicating degradation of the reduced species. In contrast, the cyclic voltammogram of $[\mathrm{Pd}(\mu-\mathrm{OH})(\mathrm{pdp})]_{2}$ presented two quasireversible reduction events with half-wave potentials at $-0.953 \mathrm{~V}(\Delta \mathrm{Ep}=84 \mathrm{mV})$ and $-1.134 \mathrm{~V}\left(\Delta \mathrm{E}_{\mathrm{p}}=86 \mathrm{mV}\right)$ (Figure 5, right panel) (Figures S9 and S10). This electrochemical profile is consistent with two sequential one-electron reductions, as observed in homoleptic propentdyopent complexes..$^{50}$ The relatively small difference in half-wave potentials $(181 \mathrm{mV})$ of the two events is indicative of partial delocalization of the first reducing equivalent over the two ligands, corresponding to Class II in the Robin-Day classification of mixed-valence compounds. ${ }^{92-95}$

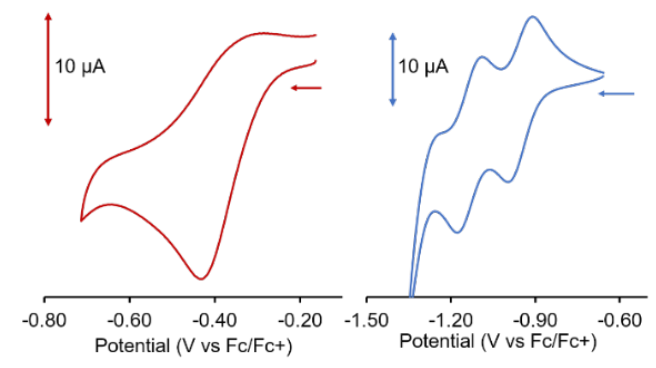

Figure 5. Cyclic voltammograms of $\left[\mathrm{Pd}\left(\mathrm{H}_{2} \mathrm{O}\right)_{2}(\mathrm{pdp})\right]\left[\mathrm{BF}_{4}\right]$ (left) and $[\mathrm{Pd}(\mu-\mathrm{OH})(\mathrm{pdp})]_{2}$ (right) at a glassy carbon electrode in $\mathrm{CH}_{2} \mathrm{Cl}_{2}$ with $\left(\mathrm{NBu}_{4}\right)\left(\mathrm{PF}_{6}\right)$ as a supporting electrolyte. Data collected at a $100 \mathrm{mV} \mathrm{s}^{-1}$ scan rate using a $\mathrm{Ag} / \mathrm{AgCl}$ pseudo-reference electrode and a Pt wire auxiliary electrode.

The redox chemistry of $[\mathrm{Pd}(\mu-\mathrm{OH})(\mathrm{pdp})]_{2}$ was further investigated by spectroelectrochemical methods (Figure 6). Upon controlled potential electrolysis at $-1.00 \mathrm{~V}$, the first reduction is accompanied by a decrease in the main absorption bands ( 372 and $585 \mathrm{~nm}$ ) with concurrent appearance of transitions at 441,675 , and $752 \mathrm{~nm}$. The presence of low-intensity, near-IR bands in the monoanionic complex is consistent with intraligand $\pi-\pi$ charge-transfer transitions associated with oligopyrrolic radicals, as previously reported. ${ }^{26,50-52}$ Furthermore, the intensity of these bands increases upon generation of the doubly-reduced species by electrolysis at $-1.3 \mathrm{~V}$ with minor wavelength shifts $(439,695$, and $758 \mathrm{~nm})$, suggesting the formation of a dianionic diradical.

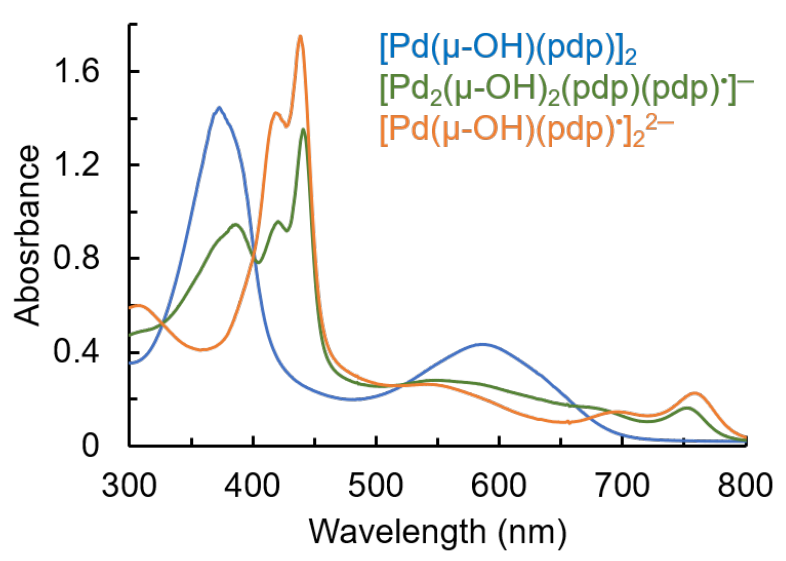

Figure 6. Spectral changes observed upon reduction of $[\mathrm{Pd}(\mu-$ $\mathrm{OH})(\mathrm{pdp})]_{2}$ (blue trace) $\left(7: 3 \mathrm{v} / \mathrm{v} \quad \mathrm{DMF}: \mathrm{CH}_{2} \mathrm{Cl}_{2}, 0.1 \mathrm{M}\right.$ $\left.\left(\mathrm{NBu}_{4}\right)\left(\mathrm{PF}_{6}\right)\right)$ by controlled potential electrolysis to produce the one-electron reduction product at $-1.00 \mathrm{~V}$ (green trace) and then the two-electron reduction product at $-1.30 \mathrm{~V}$ (orange trace).

The reduction of $[\mathrm{Pd}(\mu-\mathrm{OH})(\mathrm{pdp})]_{2}$ by chemical methods was investigated using cobaltocene $\left(\mathrm{CoCp}_{2}\right)$ in dichloromethane solutions. Anaerobic addition of either one or two equivalents of $\mathrm{CoCp}_{2}$ at room temperature led to the rapid formation of green ( 1 equiv) or orange ( 2 equiv) solutions, with absorption spectra identical to those of the electrochemically generated products. Exposure of the reduced species to air resulted in re-oxidation to the neutral complex $[\mathrm{Pd}(\mu-\mathrm{OH})(\mathrm{pdp})]_{2}$ along with partial decomposition as monitored via absorption spectroscopy (Figure S11).

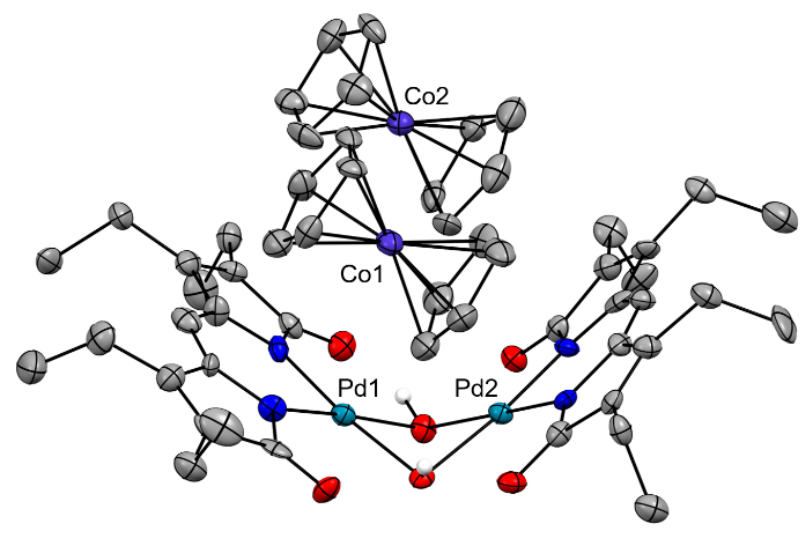

Figure 7. Crystal structure of $\left[\mathrm{CoCp}_{2}\right]_{2}\left[\mathrm{Pd}(\mu-\mathrm{OH})(\mathrm{pdp})^{\bullet}\right]_{2}$ showing a partial labeling scheme. Hydrogen atoms and solvent molecules are omitted for clarity. Non-hydrogen atoms are displayed as thermal displacement ellipsoids set at the 50\% probability level. CCDC: 2077678.

The doubly-reduced product was isolated from the reaction mixture by precipitation with pentane to afford a brown solid, and X-ray quality crystals were grown from a layered solution of $\mathrm{CH}_{2} \mathrm{Cl}_{2}$ /pentane at $-20{ }^{\circ} \mathrm{C}$ under a nitrogen atmosphere. The molecular structure obtained for these crystals (Figures 7 and S12) reveals the presence of two cobaltocenium counterions, thus confirming the successful formation of the two-electron reduction product. Readily apparent upon comparison to the neutral dimer is the increase in folding across the bridged hydroxo ligands: 
for instance, the interplanar angle between the two palladium(II) primary coordination spheres contracts from $159^{\circ}$ to $122^{\circ}$ (Figure S13). The bond lengths between palladium centers and nitrogen/oxygen donors show slight elongation upon reduction, but maintain the square planar geometry expected for a divalent oxidation state. More significant alterations are observed in the dipyrrindione ligand scaffold, particularly elongations of the terminal C$\mathrm{O}$ and alternate contractions/elongations of $\mathrm{C}-\mathrm{N}$ bonds on the pyrrolic rings (Table S4). Similar changes to the ligand framework were also observed in palladium(II) tripyrrindione complexes upon one-electron reduction, ${ }^{32}$ as well as in a bis(dipyrrinato)-Pacman dichromium complex after treatment with potassium graphite reductant. ${ }^{96}$ Overall, these changes in the dipyrrindione bond lengths support the assignment of two subsequent one-electron reductions to the ligand frameworks in $\left[\mathrm{CoCp}_{2}\right]_{2}\left[\mathrm{Pd}(\mu-\mathrm{OH})(\mathrm{pdp})^{*}\right]_{2}$.

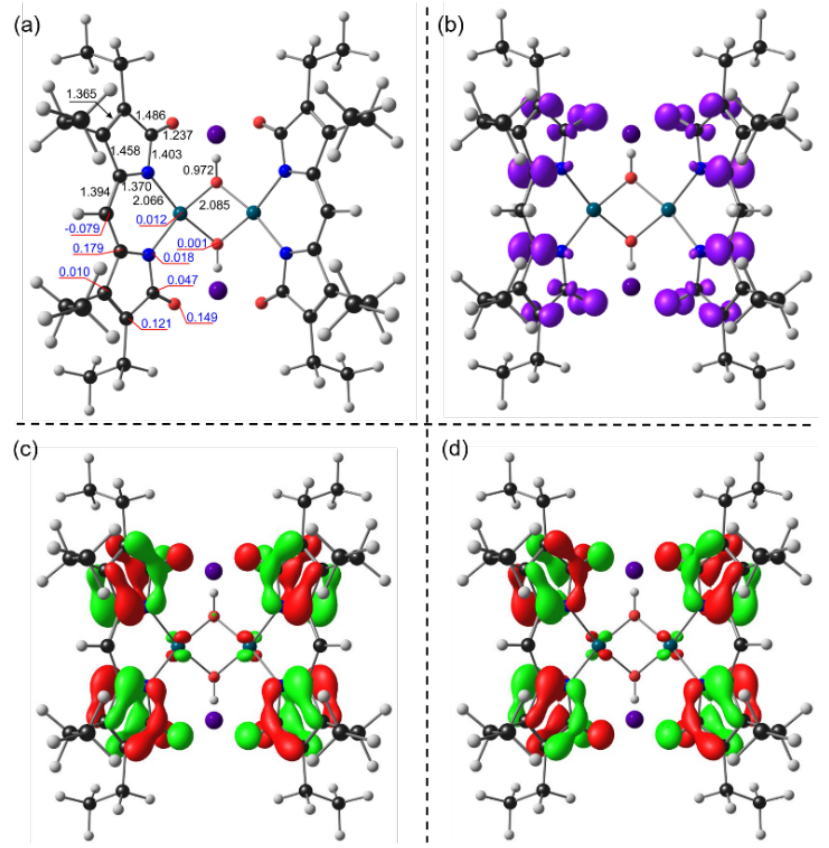

Figure 8. OLYP-D3/TZ2P computational results for diradical species $[\mathrm{Cs}]_{2}\left[\mathrm{Pd}(\mu-\mathrm{OH})(\mathrm{pdp})^{\cdot}\right]_{2}$ showing (a) selected bond distances $(\AA)$ and Mulliken spin populations in black and blue, respectively, (b) spin densities in violet, and (c-d) SOMOs with phases indicated in red and green.

Geometry optimization of the dianion dimer was performed using OLYP-D3/TZ2P with two $\mathrm{Cs}^{+}$cations (Figure S14). The bond lengths of the dipyrrindione scaffold were found to be in good agreement with the crystallographic data (Figure 8a and Table S6), whereas the calculated structure presents slightly contracted Pd-Pd distance $\left(\begin{array}{ll}2.790 & \AA\end{array}\right)$ and fold angle between dipyrrindione ligand planes (Table S8), likely associated to the size difference between the cobaltocenium and cesium cations. As expected for the product of two ligand-centered reductions, the Mulliken spin density is almost exclusively localized on the two dipyrrindione scaffolds (Figure 8b and Table S7). The two SOMOs (Figure 8 and S15) were found to be nearly degenerate and of predominantly ligand character, mirroring the spin density contours.
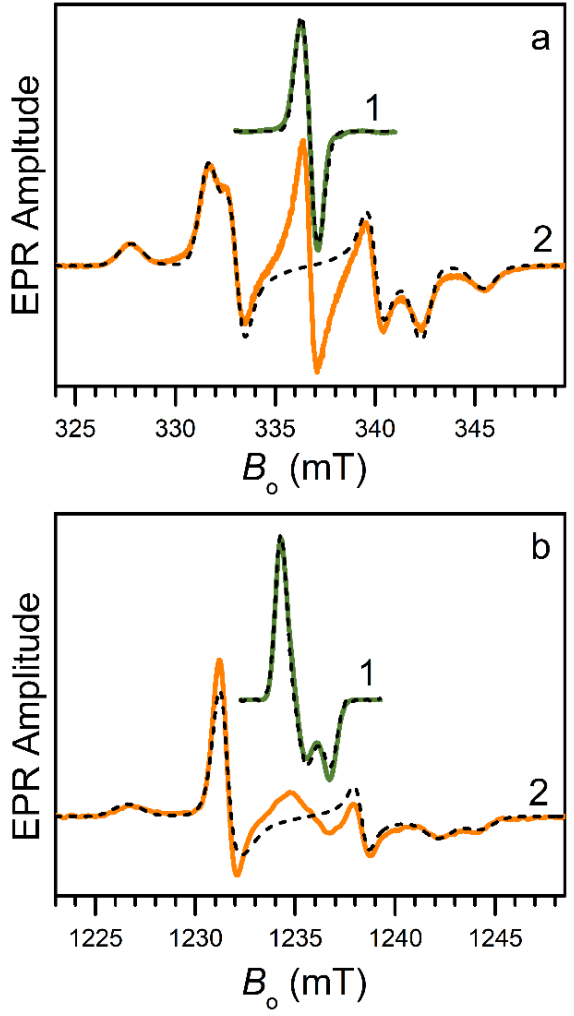

Figure 9. X-band (a) and Q-band (b) EPR spectra of the reduction products of $[\mathrm{Pd}(\mu-\mathrm{OH})(\mathrm{pdp})]_{2}$. Traces 1 and 2 correspond to the reduction with 1 and 2 equiv. of $\mathrm{CoCp}_{2}$, respectively. Simulated spectra are shown by black dashed lines. The simulation parameters are as follows: monoanionic complex gtensor, $\left(g_{1}, g_{2}, g_{3}\right)=(2.0059,2.0046,2.0019)$; dianionic complex g-tensor, $\left(g_{\mathrm{x}}, g_{\mathrm{y}}, g_{\mathrm{z}}\right)=(2.0045,2.0047,2.0022)$ and Dtensor, $\left(D_{\mathrm{x}}, D_{\mathrm{y}}, D_{\mathrm{z}}\right)=(-330,130,200) \mathrm{MHz}$. Experimental conditions and individual linewidths used in the simulations are detailed in the Experimental Section.

Further insights into the electronic structure of the reduction products were pursued by X-band and Q-band EPR measurements. The X-band EPR spectrum of the oneelectron reduction product is dominated by a single Gaussian line with the width of $0.85 \mathrm{mT}$ between the maximum slope points (Figure 9a, green trace 1). The zero crossing of this line at $B_{0}=336.7 \mathrm{mT}$ corresponds to $g \approx 2.0038$. The Q-band EPR measurement and spectrum simulation (Figure $9 \mathrm{~b}$, trace 1) resulted in a g-tensor with principal components $\left(g_{1}, g_{2}, g_{3}\right)=(2.0059,2.0046,2.0019)$. Such spectroscopic features are characteristic of an organic radical and confirm the ligand-based identity of the observed paramagnetic center. The X-band spectrum was successfully simulated (Figure 8a, dashed black trace 1) based on the gtensor parameters found from Q-band data.

For a two-electron reduction product featuring two ligand-based spins, a strong magnetic dipole interaction between the unpaired electrons is expected, and indeed, the X-band EPR spectrum (Figure 9a, orange trace 2) shows the characteristic features of a rhombic dipolar coupling. Notably, the spectrum is not exactly symmetric with respect to the central line that corresponds to residual singly reduced complex. As confirmed by the Q-band spectra (Figure 9b, orange trace 2), this asymmetry is caused by the g-factor anisotropy. The spectra were simulated suc- 
cessfully (Figure 9, black dashed traces) using a dipole interaction tensor $\left(D_{\mathrm{x}}, D_{\mathrm{y}}, D_{\mathrm{z}}\right)=(-330,130,200) \mathrm{MHz}$ aligned with the g-tensor $\left(g_{\mathrm{x}}, g_{\mathrm{y}}, g_{\mathrm{z}}\right)=(2.0045,2.0047$, 2.0022). An analysis based on the spin density distributions predicted by DFT calculations shows (Table S7 and Figure S15) that the principal axis $\mathrm{z}$ coincides with the $C_{2}$ symmetry axis of the dimeric complex (that has an overall $\mathrm{C}_{2 \mathrm{v}}$ symmetry), axis $\mathrm{x}$ points in the Pd-to-Pd direction, and axis $\mathrm{y}$ is parallel to the line joining the bridging oxygen atoms (Figure S16). This analysis also indicates that the angle between the ligand planes in the dianionic complex in solution is apparently close to $101.6^{\circ}$ as observed in the crystal structure (Figure 7). Overall, the EPR data fully confirmed the assignment of $\left[\mathrm{Pd}(\mu-\mathrm{OH})(\mathrm{pdp})^{\cdot}\right]_{2} 2^{2-}$ as a triplet diradical delocalized on the dipyrrindione ligands.

\section{CONCLUSIONS}

The coordination and redox chemistry of tetraethyl dipyrrindione, also known as propentdyopent, was investigated in heteroleptic palladium(II) complexes. The bis(aqua) palladium(II) dipyrrindione complex readily undergoes a deprotonation-driven dimerization in the presence of water to give the hydroxo-bridged dinuclear complex. The dimerization is accompanied by a $40-\mathrm{nm}$ redshift in the visible absorption spectrum and is reversible upon addition of stoichiometric amounts of protic acid. The binuclear $\mu$-hydroxo complex maintains the reversible ligandcentered redox chemistry of prior mononuclear dipyrrindione complexes and undergoes two quasi-reversible oneelectron reduction events. Chemical reduction of this binuclear complex by cobaltocene led to the doubly-reduced product. A detailed analysis by crystallography, EPR spectroscopy, and DFT calculations confirmed the formation of a dianionic diradical species wherein two SOMOs delocalized on the ligand systems result in a triplet spin state. In addition, the dipolar interaction parameters obtained by EPR experiments are consistent with the folded structure observed in the solid state, possibly featuring a $d^{8}-d^{8}$ interaction between the metal centers. The effects of different metal ions and bridging ligands on the geometry and spin interactions of dinuclear dipyrrindione complexes will be the subject of upcoming studies. This work demonstrates conclusively the stabilization of unpaired spins on the compact bidentate scaffold of dipyrrindione ligands, thus enhancing the scope of the large family of dipyrrins widely employed in catalysis, imaging, and materials science.

\section{EXPERIMENTAL}

Materials and methods. The tetraethyl dipyrrin-1,9-dione methanol adduct ( $\mathrm{Hpdp} \bullet \mathrm{MeOH})^{70,97}$ and palladium(II) acetylacetonate $\left(\mathrm{Pd}(\mathrm{acac})_{2}\right)^{98}$ were prepared as previously reported. Dichloromethane $\left(\mathrm{CH}_{2} \mathrm{Cl}_{2}\right)$, dimethylformamide (DMF), and pentane were dried by passage through a solvent purifier. All other commercial reagents were used without further purification. NMR spectra were recorded on a Bruker Advance-III $400 \mathrm{MHz}$ and a Bruker NEO-500 MHz NMR spectrometer at the NMR Spectroscopy Facility of the Department of Chemistry and Biochemistry. UVVisible spectra were obtained at ambient temperature using an Agilent 8453 UV-Vis spectrophotometer. Highresolution mass spectra (HRMS) via electrospray ioniza- tion (ESI) methods were obtained at the University of Arizona Analytical \& Biological Mass Spectrometry Core Facility. Elemental analyses were performed by NuMega Resonance Labs in San Diego, CA.

\section{Synthetic procedures}

$\left[\mathrm{Pd}\left(\mathrm{H}_{2} \mathrm{O}\right)_{2}(p d p)\right]\left[B F_{4}\right] . \mathrm{Hpdp} \bullet \mathrm{MeOH}(8.5 \mathrm{mg}, 0.027 \mathrm{mmol})$ and $\mathrm{Pd}(\mathrm{acac})_{2}(8.1 \mathrm{mg}, 0.027 \mathrm{mmol})$ were dissolved in $\mathrm{CH}_{2} \mathrm{Cl}_{2}(10 \mathrm{~mL})$ and $\mathrm{HBF}_{4}(10 \mu \mathrm{L}, 48 \%$ aqueous solution $)$ was added to the reaction mixture and stirred at room temperature for 3 hours. Upon reaction completion, as determined through UV-visible absorption spectroscopy, the solvent was removed in vacuo, and the red solid was purified by crystallization from a layered solution of $\mathrm{CH}_{2} \mathrm{Cl}_{2}$ and pentane to afford $\left[\mathrm{Pd}\left(\mathrm{H}_{2} \mathrm{O}\right)_{2}(\mathrm{pdp})\right]\left[\mathrm{BF}_{4}\right]$ as a red crystalline solid $(6.0 \mathrm{mg}, 43 \%) .{ }^{1} \mathrm{H}$ NMR $\left(500 \mathrm{MHz}^{\mathrm{CDCl}}{ }_{3}\right): \delta$ $6.66(\mathrm{~s}, 4 \mathrm{H}), 5.87(\mathrm{~s}, 1 \mathrm{H}) 2.54(\mathrm{q}, \mathrm{J}=7.7 \mathrm{~Hz}, 4 \mathrm{H}), 2.35(\mathrm{q}, \mathrm{J}=$ $7.6 \mathrm{~Hz}, 4 \mathrm{H}), 1.21(\mathrm{t}, \mathrm{J}=7.7 \mathrm{~Hz}, 6 \mathrm{H}), 1.13(\mathrm{t}, \mathrm{J}=7.6 \mathrm{~Hz}, 6 \mathrm{H})$. ${ }^{13} \mathrm{C}$ NMR $\left(125 \mathrm{MHz}, \mathrm{CDCl}_{3}\right): \delta 185.29,168.78,149.90$, 141.85, 94.92, 17.87, 17.59, 14.27, 13.16. UV-Vis $\left(\mathrm{CH}_{2} \mathrm{Cl}_{2}\right)$ $\lambda_{\max }(\varepsilon) 382(17,400), 402(16,000), 545\left(6,500 \mathrm{M}^{-1} \mathrm{~cm}^{-1}\right)$. HRMS-ESI $^{+} \quad(m / z):[\mathrm{M}]^{+}$calcd. for $\left[\mathrm{C}_{17} \mathrm{H}_{25} \mathrm{~N}_{2} \mathrm{O}_{4} \mathrm{Pd}\right]$, 427.0849; found, 427.0845. Anal. Calcd. For [ $\left.\mathrm{C}_{17} \mathrm{H}_{25} \mathrm{~N}_{2} \mathrm{O}_{4} \mathrm{BF}_{4} \mathrm{Pd}\right]: \mathrm{C}, 39.7 ; \mathrm{H}, 4.9 ; \mathrm{N}, 5.4 \%$; found: $\mathrm{C}, 39.8$; $\mathrm{H}, 4.5 ; \mathrm{N}, 5.5 \%$.

$[\mathrm{Pd}(\mu-\mathrm{OH})(p d p)]_{2} .\left[\mathrm{Pd}\left(\mathrm{H}_{2} \mathrm{O}\right)_{2}(\mathrm{pdp})\right]\left[\mathrm{BF}_{4}\right](7.6 \mathrm{mg}, 0.0148$ mmol) was dissolved in $\mathrm{CH}_{2} \mathrm{Cl}_{2}(15 \mathrm{~mL})$ and shaken with deionized water $(20 \mathrm{~mL})$ in a separatory funnel until the organic layer fully converted from red to blue. The organic layer was further washed with brine and dried over $\mathrm{Na}_{2} \mathrm{SO}_{4}$, and solvent was removed in vacuo. The resulting blue solid was purified by crystallization from a layered solution of $\mathrm{CH}_{2} \mathrm{Cl}_{2}$ and pentane to afford $[\mathrm{Pd}(\mu-\mathrm{OH})(\mathrm{pdp})]_{2}$ as a blue crystalline solid (5.3 mg, 88\%). ${ }^{1} \mathrm{H}$ NMR (500 $\mathrm{MHz}_{\mathrm{CDCl}}$ ): $\delta 5.55(\mathrm{~s}, 2 \mathrm{H}), 3.07(\mathrm{~s}, 2 \mathrm{H}), 2.47(\mathrm{q}, \mathrm{J}=7.7 \mathrm{~Hz}$, $8 \mathrm{H}), 2.33(\mathrm{q}, \mathrm{J}=7.6 \mathrm{~Hz}, 8 \mathrm{H}), 1.14(\mathrm{t}, \mathrm{J}=7.7 \mathrm{~Hz}, 12 \mathrm{H}), 1.07(\mathrm{t}$, $\mathrm{J}=7.6 \mathrm{~Hz}, 12 \mathrm{H}) \cdot{ }^{13} \mathrm{C} \mathrm{NMR}\left(125 \mathrm{MHz}, \mathrm{CDCl}_{3}\right): \delta 182.04$, 167.82, 148.04, 139.85, 91.66, 17.85, 17.39, 14.69, 13.70. UV-Vis $\left(\mathrm{CH}_{2} \mathrm{Cl}_{2}\right) \lambda_{\max }(\varepsilon) 372(42,600), 585\left(12,400 \mathrm{M}^{-1} \mathrm{~cm}^{-}\right.$

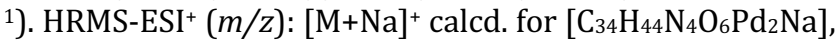
841.1227; found, 841.1237. Anal. Calcd. For [ $\mathrm{C}_{34} \mathrm{H}_{44} \mathrm{~N}_{4} \mathrm{O}_{6} \mathrm{Pd}_{2}$ ]: C, 49.9; $\mathrm{H}, 5.4 ; \mathrm{N}, 6.8 \%$; found: $\mathrm{C}, 49.8 ; \mathrm{H}$, $5.1 ; \mathrm{N}, 6.9 \%$.

$\left[\mathrm{CoCp}_{2}\right]_{2}[\mathrm{Pd}(\mu-\mathrm{OH})(p d p) \cdot]_{2} . \quad[\mathrm{Pd}(\mu-\mathrm{OH})(\mathrm{pdp})]_{2} \quad(7.8 \mathrm{mg}$, $0.0095 \mathrm{mmol})$ was dissolved in $\mathrm{CH}_{2} \mathrm{Cl}_{2}(1.5 \mathrm{~mL})$ in a glovebox. $\mathrm{CoCp}_{2}$ (5.2 mg, $0.0275 \mathrm{mmol}$ ) reductant was dissolved in $\mathrm{CH}_{2} \mathrm{Cl}_{2}(2.0 \mathrm{~mL})$ to give a $13.75 \mathrm{mM}$ stock solution, 1.40 $\mathrm{mL}(0.01925 \mathrm{mmol}, 2$ equiv.) of which were added to the solution of $[\mathrm{Pd}(\mu-\mathrm{OH})(\mathrm{pdp})]_{2}$. After stirring for three minutes, pentane was added to the reaction mixture to form a brown precipitate. The brown solid was isolated via vacuum filtration and washed with additional pentane to afford $\left[\mathrm{CoCp}_{2}\right]_{2}\left[\mathrm{Pd}(\mu-\mathrm{OH})(\mathrm{pdp})^{\bullet}\right]_{2}(8.0 \mathrm{mg}, 70 \%)$. Anal. Calcd. For $\left[\mathrm{C}_{54} \mathrm{H}_{63} \mathrm{~N}_{4} \mathrm{O}_{6} \mathrm{Pd}_{2} \mathrm{Co}_{2} \bullet 1.5 \mathrm{CH}_{2} \mathrm{Cl}_{2}\right]: \mathrm{C}, 50.4 ; \mathrm{H}, 5.1 ; \mathrm{N}$, 4.2\%; found: C, 50.5; H, 4.9; N, 4.2\%.

\section{$X$-ray diffraction analysis}

The single crystal X-ray diffraction measurements were performed at the XRD facility of the University of Arizona, Department of Chemistry and Biochemistry, on a Bruker Kappa APEX II Duo diffractometer equipped APEX II CCD area detector, four-circle kappa goniometer, and an Oxford Cryostream low-temperature system. The data collection was performed at $100 \mathrm{~K}$, using the Mo-K $\mathrm{K}_{\alpha}$ radiation $(\lambda=$ 
$0.71073 \AA$ ). During the measurements, the instrument was controlled by the APEX2 software package (Bruker AXS Inc., Madison, WI, 2007). The absorption correction was done using a multi-scan method implemented in SADABS (Sheldrick, G. M. University of Göttingen, Germany, 1997).

The crystal structures were solved and refined using the SHELX package ${ }^{99}$ called from the Olex $2^{100}$ GUI. All non-H atoms were located in the Fourier map and were refined anisotropically. The carbon-bound hydrogen atoms were calculated in ideal positions with isotropic displacement parameters set to $1.2 U_{e q}$ of the attached atom $\left(1.5 U_{e q}\right.$ for methyl hydrogen atoms); their positions were then refined using a riding model. The relevant experimental and structure refinement details are available in Table S2.

Structure refinement of $\left[\mathrm{Pd}\left(\mathrm{H}_{2} \mathrm{O}\right)_{2}(p d p)\right]\left[\mathrm{BF}_{4}\right]$. Crystals grew as red plates by slow diffusion of hexanes into a solution of $\mathrm{CH}_{2} \mathrm{Cl}_{2}$ at room temperature. Data were solved and refined in the triclinic space group P-1. The asymmetric unit cell contained one complex. $Q$-peaks for the hydrogenbound $\mathrm{O}-\mathrm{H}$ protons were located in the Fourier map, and hydrogens were assigned to those positions and refined. The four fluorine atoms (F1, F2, F3, and F4) of the tetrafluoroborate anion were found to be disordered by a rotational distribution around the boron atom. The disorder was modeled by a distribution over two positions to provide a stable refinement. The highest residual Fourier peak found in the model was +1.70 e $\AA^{-3}$ approx. $0.88 \AA$ from F3A, and the deepest Fourier hole was -0.86 e $\AA^{-3}$ approx. $0.75 \AA$ away from F4.

Structure refinement of $[\mathrm{Pd}(\mu-\mathrm{OH})(p d p)]_{2}$. Crystals grew as red plates by slow diffusion of hexanes into $\mathrm{CH}_{2} \mathrm{Cl}_{2}$ at room temperature. Data were solved and refined in the triclinic space group P-1. The asymmetric unit cell contained three complexes. $Q$-peaks for hydrogen-bound $\mathrm{O}-\mathrm{H}$ protons were located in the Fourier map, and hydrogens were assigned to those positions and refined. The highest residual Fourier peak found in the model was +0.98 e $\AA^{-3}$ approx. $0.89 \AA$ away from $\mathrm{Pd} 1 \mathrm{C}$, and the deepest Fourier hole was $-0.58 e \AA^{-3}$ approx. $0.74 \AA$ away from Pd2C.

Structure refinement of $\left[\mathrm{CoCp}_{2}\right]_{2}[\mathrm{Pd}(\mu-\mathrm{OH})(p d p)]_{2}$. Crystals grew as brown-orange plates by slow diffusion of pentane into $\mathrm{CH}_{2} \mathrm{Cl}_{2}$ at $-20{ }^{\circ} \mathrm{C}$. Data were solved and refined in the orthorhombic space group P $2{ }_{1} 2{ }_{1} 21_{1}$. The highest residual Fourier peak found in the model was +1.05 e $\AA^{-3}$ approx. $1.29 \AA$ away from 06, and the deepest Fourier hole was - 0.84 e $\AA^{-3}$ approx. $0.87 \AA$ away from Co2. The hydrogen atoms on bridging oxygens 05 and 06 were restrained to bond lengths of $1.00 \AA$ using DFIX.

\section{Computational methods}

DFT calculations with full geometry optimizations were carried out with the ADF 2018 program system. ${ }^{101}$ A variety of exchange-correlation functionals were tested; the results quoted are those for OLYP,102,103 one of the better generalized gradient approximations that we have tested extensively on a variety of transition metalcontaining systems, ${ }^{104-106}$ augmented with Grimme's D3 ${ }^{107}$ dispersion corrections. All-electron Slater-type triple-z plus double polarization (STO-TZ2P) basis sets were used throughout. Point group symmetry was exploited, both in the interest of greater insight and to calculate electronic states with different orbital occupancies. Key results were checked against other pure, hybrid, and range-separated functionals and found to be stable.

\section{Electrochemical measurements}

Cyclic voltammograms were performed on a Gamry Reference 600 potentiostat utilizing a single-compartment cell with three electrodes: a glassy carbon working electrode, a platinum wire auxiliary electrode, and a $\mathrm{Ag} / \mathrm{AgCl}$ quasireference electrode. Measurements were performed at ambient temperature under an inert argon atmosphere in $\mathrm{CH}_{2} \mathrm{Cl}_{2}$ containing $0.1 \mathrm{M}\left(\mathrm{NBu}_{4}\right)\left(\mathrm{PF}_{6}\right)$ (triply recrystallized) as a supporting electrolyte. Sample concentrations were 1$2 \mathrm{mM}$, and all electrochemical data were internally referenced to the ferrocene/ferrocenium couple (set at $0.00 \mathrm{~V}$ ). Spectroelectrochemical measurements were performed using a three-electrode electrochemical quartz cell with a $1.0 \mathrm{~mm}$ path length, an $\mathrm{Au}$ gauze working electrode, Ag wire quasi-reference electrode, and a Pt wire counter electrode. The complex was dissolved in 70:30 (v/v) DMF: $\mathrm{CH}_{2} \mathrm{Cl}_{2}$ containing $0.1 \mathrm{M}\left(\mathrm{NBu}_{4}\right)\left(\mathrm{PF}_{6}\right)$.

\section{EPR measurements and simulations}

The EPR measurements were performed at two microwave (mw) bands: $\mathrm{X}(\sim 9.5 \mathrm{GHz})$ and $\mathrm{Q}(\sim 34 \mathrm{GHz})$. In the $\mathrm{X}$ band experiments, a continuous-wave EPR spectrometer Elexsys E500 (Bruker Biospin) equipped with a rectangular $\mathrm{TE}_{102}$ resonator was used with experimental conditions as follows: mw frequency, $9.441 \mathrm{GHz}$; mw power, $20 \mu \mathrm{W}$; magnetic field modulation amplitude, $0.2 \mathrm{mT}$. The measurement temperature of $77 \mathrm{~K}$ was achieved by using liquid nitrogen in a finger dewar.

The Q-band measurements were performed on a homebuilt pulsed EPR spectrometer ${ }^{108}$ equipped with a cylindrical TE 011 resonator and a helium gas flow cryostat (CF935, Oxford Instruments). The EPR spectra were obtained by taking a numerical first derivative of electron spin echo (ESE) field sweep spectra. Experimental conditions: mw frequency, $34.644 \mathrm{GHz}$; mw pulse durations, 140 and 250 ns; time interval $\tau$ between the pulses, $350 \mathrm{~ns}$; boxcar integration gate, $150 \mathrm{~ns}$; measurement temperature, $15 \mathrm{~K}$.

The numerical simulations of the EPR spectra were performed using custom software based on the exact diagonalization of the spin Hamiltonian. In the simulations of the spectrum of the dianionic complex, the $\mathrm{C}_{2 \mathrm{v}}$ symmetry was taken into account. This symmetry determines the directions of the magnetic axes with respect to the complex (along the $\mathrm{C}_{2}$ axis, along the line joining the bridging oxygen atoms, and along the line joining the Pd ions) and requires that the g- and D-tensors are coaxial. The spectroscopic parameters resulting from the simulations are as follows. For the one-electron reduction product, the $\mathrm{g}$ tensor is $\left(g_{1}, g_{2}, g_{3}\right)=(2.0059,2.0046,2.0019)$. The individual linewidths used are $\left(\delta B_{1}, \delta B_{2}, \delta B_{3}\right)=(0.75,0.75$, $0.75) \mathrm{mT}$ for the $\mathrm{X}$-band simulation, and $\left(\delta B_{1}, \delta B_{2}, \delta B_{3}\right)=$ $(0.5,0.8,0.65) \mathrm{mT}$ for the Q-band simulation. The simulation parameters for the 2-electron reduction product are: g-tensor, $\left(g_{\mathrm{x}}, g_{\mathrm{y}}, g_{\mathrm{z}}\right)=(2.0045,2.0047,2.0022)$; D-tensor, $\left(D_{\mathrm{x}}, D_{\mathrm{y}}, D_{\mathrm{z}}\right)=(-330,130,200) \mathrm{MHz}$; individual linewidths for X-band, $\left(\delta B_{\mathrm{x}}, \delta B_{\mathrm{y}}, \delta B_{\mathrm{z}}\right)=(1.27,0.7,0.85) \mathrm{mT}$; individual linewidths for Q-band, $\left(\delta B_{\mathrm{x}}, \delta B_{\mathrm{y}}, \delta B_{\mathrm{z}}\right)=(1.4,0.6,1.4) \mathrm{mT}$. 


\section{ASSOCIATED CONTENT}

Supporting Information. This material is available free of charge via the Internet at http://pubs.acs.org.

Optical absorption data, NMR data, X-ray crystallography data, electrochemical data, computational details, EPR analysis data, supporting figures and tables (PDF).

\section{AUTHOR INFORMATION}

\section{Corresponding Authors}

*Elisa Tomat - Department of Chemistry and Biochemistry, The University of Arizona, 1306 E. University Blvd., Tucson AZ 85721, USA

Email: tomat@arizona.edu

*Abhik Ghosh - Department of Chemistry, UiT - The Arctic University of Norway, N-9037 Tromsø, Norway

Email: abhik.ghosh@uit.no

\section{Author Contributions}

The manuscript was written through contributions of all authors. All authors have given approval to the final version of the manuscript.

Notes

The authors declare no competing financial interests.

\section{ACKNOWLEDGMENTS}

This work was supported by the National Science Foundation (CAREER award CHE-1454047 to E. T.), the Research Council of Norway (grant no. 262229 to A. G.), and the South African National Research Fund (grant nos. 129270 and 132504 to J. C.). The Bruker NEO-500 spectrometer in the UArizona Dept. of Chemistry and Biochemistry NMR Facility was purchased thanks to support from the National Science Foundation (MRI award CHE-1920234).

\section{REFERENCES}

(1) Luca, O. R.; Crabtree, R. H. Redox-Active Ligands in Catalysis. Chem. Soc. Rev. 2013, 42, 1440-1459.

(2) van der Vlugt, J. I. Radical-Type Reactivity and Catalysis by Single-Electron Transfer to or from Redox-Active Ligands. Chem. Eur. J. 2019, 25, 2651-2662.

(3) Demir, S.; Jeon, I.-R.; Long, J. R.; Harris, T. D. Radical LigandContaining Single-Molecule Magnets. Coord. Chem. Rev. 2015, 289-290, 149-176.

(4) Ding, B.; Solomon, M. B.; Leong, C. F.; D’Alessandro, D. M. RedoxActive Ligands: Recent Advances towards Their Incorporation into Coordination Polymers and Metal-Organic Frameworks. Coord. Chem. Rev. 2021, 439, 213891.

(5) McGuire, J.; Miras, H. N.; Donahue, J. P.; Richards, E.; Sproules, S. Ligand Radicals as Modular Organic Electron Spin Qubits. Chem. Eur. J. 2018, 24, 17598-17605.

(6) McGuire, J.; Miras, H. N.; Richards, E.; Sproules, S. Enabling Single Qubit Addressability in a Molecular Semiconductor Comprising Gold-Supported Organic Radicals. Chem. Sci. 2019, 10, 14831491.

(7) Huang, X.; Groves, J. T. Oxygen Activation and Radical Transformations in Heme Proteins and Metalloporphyrins. Chem. Rev. 2018, 118, 2491-2553.

(8) Stillman, M. Formation and Electronic Properties of RingOxidized and Ring-Reduced Radical Species of the Phthalocyanines and Porphyrins. J. Porphyrins Phthalocyanines 2000, 04, 374-376.

(9) Walker, F. A.; Licoccia, S.; Paolesse, R. Iron Corrolates: Unambiguous Chloroiron(III) (Corrolate)2- $\pi$-Cation Radicals. J. Inorg. Biochem. 2006, 100, 810-837.

(10) Ye, S.; Tuttle, T.; Bill, E.; Simkhovich, L.; Gross, Z.; Thiel, W.; Neese, F. The Electronic Structure of Iron Corroles: A Combined
Experimental and Quantum Chemical Study. Chem. Eur. J. 2008, 14, 10839-10851.

(11) Schweyen, P.; Brandhorst, K.; Wicht, R.; Wolfram, B.; Bröring, M. The Corrole Radical. Angew. Chem., Int. Ed. 2015, 54, 8213-8216.

(12) Ghosh, A. Electronic Structure of Corrole Derivatives: Insights from Molecular Structures, Spectroscopy, Electrochemistry, and Quantum Chemical Calculations. Chem. Rev. 2017, 117, 37983881.

(13) Ganguly, S.; Ghosh, A. Seven Clues to Ligand Noninnocence: The Metallocorrole Paradigm. Acc. Chem. Res. 2019, 52, 2003-2014.

(14) Shimizu, D.; Osuka, A. Porphyrinoids as a Platform of Stable Radicals. Chem. Sci. 2018, 9, 1408-1423.

(15) Kato, K.; Osuka, A. Platforms for Stable Carbon-Centered Radicals. Angew. Chem., Int. Ed. 2019, 58, 8978-8986.

(16) Blusch, L. K.; Craigo, K. E.; Martin-Diaconescu, V.; McQuarters, A B.; Bill, E.; Dechert, S.; DeBeer, S.; Lehnert, N.; Meyer, F. Hidden Non-Innocence in an Expanded Porphyrin: Electronic Structure of the Siamese-Twin Porphyrin's Dicopper Complex in Different Oxidation States. J. Am. Chem. Soc. 2013, 135, 13892-13899.

(17) Fukuzumi, S.; Ohkubo, K.; Ishida, M.; Preihs, C.; Chen, B.; Borden, W. T.; Kim, D.; Sessler, J. L. Formation of Ground State Triplet Diradicals from Annulated Rosarin Derivatives by Triprotonation. J. Am. Chem. Soc. 2015, 137, 9780-9783.

(18) Vogel, A.; Dechert, S.; Brückner, C.; Meyer, F. Reaching across the Divide: How Monometalation of One Binding Pocket Affects the Empty Binding Pocket in a Siamese-Twin Porphyrin Palladium Complex. Inorg. Chem. 2017, 56, 2221-2232.

(19) Firmansyah, D.; Hong, S.-J.; Dutta, R.; He, Q.; Bae, J.; Jo, H.; Kim, H.; Ok, K. M.; Lynch, V. M.; Byon, H. R.; Sessler, J. L.; Lee, C.-H. Trapping of Stable $[4 n+1] \pi$-Electron Species from Peripherally Substituted, Conformationally Rigid, Antiaromatic Hexaphyrins. Chem. Eur. J. 2019, 25, 3525-3531.

(20) Tomat, E. Coordination Chemistry of Linear Tripyrroles: Promises and Perils. Comments Inorg. Chem. 2016, 36, 327-342.

(21) Bröring, M. Beyond Dipyrrins: Coordination Interactions and Templated Macrocyclizations of Open-Chain Oligopyrroles. In Handbook of Porphyrin Science; Handbook of Porphyrin Science; World Scientific Publishing Company, 2010; Vol. Volume 8, pp 343-501.

(22) Attar, S.; Balch, A. L.; Van Calcar, P. M.; Winkler, K. Electron Transfer Behavior and Solid State Structures of the Helical Cobalt Complexes of the Open-Chain Tetrapyrrole Ligand, Octaethylbilindione. J. Am. Chem. Soc. 1997, 119, 3317-3323.

(23) Balch, A. L.; Mazzanti, M.; Noll, B. C.; Olmstead, M. M. Geometric and Electronic Structure and Dioxygen Sensitivity of the Copper Complex of Octaethylbilindione, a Biliverdin Analog. J. Am. Chem. Soc. 1993, 115, 12206-12207.

(24) Lord, P. A.; Olmstead, M. M.; Balch, A. L. Redox Characteristics of Nickel and Palladium Complexes of the Open-Chain Tetrapyrrole Octaethylbilindione: A Biliverdin Model. Inorg. Chem. 2000, 39, 1128-1134.

(25) Kochem, A.; Chiang, L.; Baptiste, B.; Philouze, C.; Leconte, N.; Jarjayes, O.; Storr, T.; Thomas, F. Ligand-Centered Redox Activity in Cobalt(II) and Nickel(II) Bis(Phenolate)-Dipyrrin Complexes. Chem. Eur. J. 2012, 18, 14590-14593.

(26) Lecarme, L.; Chiang, L.; Moutet, J.; Leconte, N.; Philouze, C.; Jarjayes, O.; Storr, T.; Thomas, F. The Structure of a One-Electron Oxidized Mn(III)-Bis(Phenolate)Dipyrrin Radical Complex and Oxidation Catalysis Control via Ligand-Centered Redox Activity. Dalton Trans. 2016, 45, 16325-16334.

(27) Yamamura, M.; Takizawa, H.; Gobo, Y.; Nabeshima, T. Stable Neutral Radicals of Planar N202-Type Dipyrrin Platinum Complexes: Hybrid Radicals of the Delocalized Organic $\pi$-Orbital and Platinum d-Orbital. Dalton Trans. 2016, 45, 6834-6838.

(28) Shan, W.; Desbois, N.; Pacquelet, S.; Brandès, S.; Rousselin, Y.; Conradie, J.; Ghosh, A.; Gros, C. P.; Kadish, K. M. Ligand Noninnocence in Cobalt Dipyrrin-Bisphenols: Spectroscopic, Electrochemical, and Theoretical Insights Indicating an Emerging Analogy with Corroles. Inorg. Chem. 2019, 58, 76777689.

(29) Thomas, K. E.; Desbois, N.; Conradie, J.; Teat, S. J.; Gros, C. P.; Ghosh, A. Gold Dipyrrin-Bisphenolates: A Combined Experimental and DFT Study of Metal-Ligand Interactions. RSC Adv. 2020, 10, 533-540.

(30) Moutet, J.; Philouze, C.; du Moulinet d'Hardemare, A.; Leconte, N.; 
Thomas, F. Ni(II) Complexes of the Redox-Active Bis(2Aminophenyl)Dipyrrin: Structural, Spectroscopic, and Theoretical Characterization of Three Members of an Electron Transfer Series. Inorg. Chem. 2017, 56, 6380-6392.

(31) Pankhurst, J. R.; Bell, N. L.; Zegke, M.; Platts, L. N.; Lamfsus, C. A.; Maron, L.; Natrajan, L. S.; Sproules, S.; Arnold, P. L.; Love, J. B. Inner-Sphere vs. Outer-Sphere Reduction of Uranyl Supported by a Redox-Active, Donor-Expanded Dipyrrin. Chem. Sci. 2017, 8 , 108-116.

(32) Gautam, R.; Loughrey, J. J.; Astashkin, A. V.; Shearer, J.; Tomat, E. Tripyrrindione as a Redox-Active Ligand: Palladium(II) Coordination in Three Redox States. Angew. Chem., Int. Ed. 2015 54, 14894-14897.

(33) Bahnmüller, S.; Plotzitzka, J.; Baabe, D.; Cordes, B.; Menzel, D.; Schartz, K.; Schweyen, P.; Wicht, R.; Bröring, M. Hexaethyltripyrrindione (H3Et6tpd): A Non-Innocent Ligand Forming Stable Radical Complexes with Divalent TransitionMetal Ions. Eur. J. Inorg. Chem. 2016, 2016, 4761-4768.

(34) Gautam, R.; Astashkin, A. V; Chang, T. M.; Shearer, J.; Tomat, E. Interactions of Metal-Based and Ligand-Based Electronic Spins in Neutral Tripyrrindione $\pi$ Dimers. Inorg. Chem. 2017, 56, 6755-6762.

(35) Gautam, R.; Petritis, S. J.; Astashkin, A. V; Tomat, E. Paramagnetism and Fluorescence of Zinc(II) Tripyrrindione: A Luminescent Radical Based on a Redox-Active Biopyrrin. Inorg. Chem. 2018, 57, 15240-15246.

(36) Chang, M.-C.; McNeece, A. J.; Hill, E. A.; Filatov, A. S.; Anderson, J. S. Ligand-Based Storage of Protons and Electrons in Dihydrazonopyrrole Complexes of Nickel. Chem. Eur. J. 2018, 24, 8001-8008.

(37) McNeece, A. J.; Jesse, K. A.; Xie, J.; Filatov, A. S.; Anderson, J. S. Generation and Oxidative Reactivity of a Ni(II) Superoxo Complex via Ligand-Based Redox Non-Innocence. J. Am. Chem. Soc. 2020, 142, 10824-10832.

(38) Wood, T. E.; Thompson, A. Advances in the Chemistry of Dipyrrins and Their Complexes. Chem. Rev. 2007, 107, 18311861.

(39) Halper, S. R.; Cohen, S. M. Heterometallic Metal-Organic Frameworks Based on Tris(Dipyrrinato) Coordination Complexes. Inorg. Chem. 2005, 44, 486-488.

(40) Matsuoka, R.; Toyoda, R.; Sakamoto, R.; Tsuchiya, M.; Hoshiko, K.; Nagayama, T.; Nonoguchi, Y.; Sugimoto, K.; Nishibori, E.; Kawai, T.; Nishihara, H. Bis(Dipyrrinato)Metal(II) Coordination Polymers: Crystallization, Exfoliation into Single Wires, and Electric Conversion Ability. Chem. Sci. 2015, 6, 2853-2858.

(41) Sakamoto, R.; Iwashima, T.; Tsuchiya, M.; Toyoda, R.; Matsuoka, R.; Kögel, J. F.; Kusaka, S.; Hoshiko, K.; Yagi, T.; Nagayama, T. Nishihara, H. New Aspects in Bis and Tris(Dipyrrinato)Metal Complexes: Bright Luminescence, Self-Assembled Nanoarchitectures, and Materials Applications. J. Mater. Chem. A 2015, 3, 15357-15371.

(42) Wilding, M. J. T.; Iovan, D. A.; Wrobel, A. T.; Lukens, J. T.; MacMillan, S. N.; Lancaster, K. M.; Betley, T. A. Direct Comparison of $\mathrm{C}-\mathrm{H}$ Bond Amination Efficacy through Manipulation of Nitrogen-Valence Centered Redox: Imido versus Iminyl. J. Am Chem. Soc. 2017, 139, 14757-14766.

(43) Baek, Y.; Betley, T. A. Catalytic C-H Amination Mediated by Dipyrrin Cobalt Imidos. J. Am. Chem. Soc. 2019, 141, 7797-7806.

(44) Kowada, T.; Maeda, H.; Kikuchi, K. BODIPY-Based Probes for the Fluorescence Imaging of Biomolecules in Living Cells. Chem. Soc Rev. 2015, 44, 4953-4972.

(45) Baudron, S. A. Luminescent Dipyrrin Based Metal Complexes Dalton Trans. 2013, 42, 7498-7509.

(46) Kolemen, S.; Akkaya, E. U. Reaction-Based BODIPY Probes for Selective Bio-Imaging. Coord. Chem. Rev. 2018, 354, 121-134.

(47) Bessette, A.; Hanan, G. S. Design, Synthesis and Photophysical Studies of Dipyrromethene-Based Materials: Insights into Their Applications in Organic Photovoltaic Devices. Chem. Soc. Rev 2014, 43, 3342-3405.

(48) Li, G.; Hu, K.; Robson, K. C. D.; Gorelsky, S. I.; Meyer, G. J.; Berlinguette, C. P.; Shatruk, M. Tris-Heteroleptic RutheniumDipyrrinate Chromophores in a Dye-Sensitized Solar Cell. Chem. Eur. J. 2015, 21, 2173-2181.

(49) Nepomnyashchii, A. B.; Cho, S.; Rossky, P. J.; Bard, A. J. Dependence of Electrochemical and Electrogenerated
Chemiluminescence Properties on the Structure of BODIPY Dyes. Unusually Large Separation between Sequential Electron Transfers. J. Am. Chem. Soc. 2010, 132, 17550-17559.

(50) Gautam, R.; Chang, T. M.; Astashkin, A. V; Lincoln, K. M.; Tomat, E. Propentdyopent: The Scaffold of a Heme Metabolite as an Electron Reservoir in Transition Metal Complexes. Chem. Commun. 2016, 52, 6585-6588.

(51) Gautam, R.; Petritis, S. J.; Tomat, E. Redox-Switchable Cyan Fluorescence of a BODIPY Analog Inspired by Propentdyopent Pigments. Eur. J. Inorg. Chem. 2019, 2019, 68-72.

(52) Curtis, C. J.; Tomat, E. Heteroleptic Palladium(II) Complexes of Dipyrrin-1,9-Dione Supported by Intramolecular Hydrogen Bonding. J. Porphyrins Phthalocyanines 2020, 24, 112-120.

(53) Falk, H. The Chemistry of Linear Oligopyrroles and Bile Pigments; Springer-Verlag, 1989.

(54) Tomat, E. Propentdyopents: Brief History of a Family of Dipyrrolic Pigments. J. Porphyrins Phthalocyanines 2019, 23, 1265-1272.

(55) Doboneck, H. Von. 10 - The Stokvis Reaction. In The Porphyrins; Dolphin, D. B., Ed.; Academic Press: New York, 1979; pp 651662.

(56) Koerner, R.; Olmstead, M. M.; Van Calcar, P. M.; Winkler, K.; Balch, A. L. Carbon Monoxide Production during the Oxygenation of Cobalt Complexes of Linear Tetrapyrroles. Formation and Characterization of $\mathrm{Co}(\mathrm{II})($ Tetraethylpropentdyopent Anion)2. Inorg. Chem. 1998, 37, 982-988.

(57) Abe, M. Diradicals. Chem. Rev. 2013, 113, 7011-7088.

(58) Chaudhuri, P.; Verani, C. N.; Bill, E.; Bothe, E.; Weyhermüller, T.; Wieghardt, K. Electronic Structure of Bis(oIminobenzosemiquinonato)Metal Complexes ( $\mathrm{Cu}, \mathrm{Ni}, \mathrm{Pd})$. The Art of Establishing Physical Oxidation States in Transition-Metal Complexes Containing Radical Ligands. J. Am. Chem. Soc. 2001 123, 2213-2223.

(59) Kokatam, S.; Weyhermüller, T.; Bothe, E.; Chaudhuri, P.; Wieghardt, K. Structural Characterization of Four Members of the Electron-Transfer Series [PdII(L)2)2]n $(\mathrm{L}=0$ Iminophenolate Derivative; $\mathrm{n}=2-, 1-, 0,1+, 2+)$. Ligand Mixed Valency in the Monocation and Monoanion with $S=1 / 2$ Ground States. Inorg. Chem. 2005, 44, 3709-3717.

(60) Poddel'sky, A. I.; Cherkasov, V. K.; Abakumov, G. A. Transition Metal Complexes with Bulky 4,6-Di-Tert-Butyl-N-Aryl(Alkyl)-oIminobenzoquinonato Ligands: Structure, EPR and Magnetism. Coord. Chem. Rev. 2009, 253, 291-324.

(61) Herebian, D.; Bothe, E.; Neese, F.; Weyhermüller, T.; Wieghardt, K. Molecular and Electronic Structures of Bis-(oDiiminobenzosemiquinonato)Metal(II) Complexes (Ni, Pd, Pt) Their Monocations and -Anions, and of Dimeric Dications Containing Weak Metal-Metal Bonds. J. Am. Chem. Soc. 2003 125, 9116-9128.

(62) Ciccione, J.; Leconte, N.; Luneau, D.; Philouze, C.; Thomas, F. Geometric and Electronic Structures of Nickel(II) Complexes of Redox Noninnocent Tetradentate Phenylenediamine Ligands Inorg. Chem. 2016, 55, 649-665.

(63) Blanchard, S.; Neese, F.; Bothe, E.; Bill, E.; Weyhermüller, T.; Wieghardt, K. Square Planar vs Tetrahedral Coordination in Diamagnetic Complexes of Nickel(II) Containing Two Bidentate $\pi$-Radical Monoanions. Inorg. Chem. 2005, 44, 3636-3656.

(64) Lu, C. C.; Bill, E.; Weyhermüller, T.; Bothe, E.; Wieghardt, K. Neutral Bis( $\alpha$-Iminopyridine)Metal Complexes of the First-Row Transition Ions (Cr, Mn, Fe, Co, Ni, Zn) and Their Monocationic Analogues: Mixed Valency Involving a Redox Noninnocent Ligand System. J. Am. Chem. Soc. 2008, 130, 3181-3197.

(65) van Gastel, M.; Lu, C. C.; Wieghardt, K.; Lubitz, W. Electron Paramagnetic Resonance and Electron Nuclear Double Resonance Investigation of the Diradical $\operatorname{Bis}(\alpha$ Iminopyridinato)Zinc Complex. Inorg. Chem. 2009, 48, 26262632.

(66) Roy, S.; Pramanik, S.; Patra, S. C.; Adhikari, B.; Mondal, A Ganguly, S.; Pramanik, K. Ambient-Stable Bis-AzoaromaticCentered Diradical $[(\mathrm{L} \bullet) \mathrm{M}(\mathrm{L} \bullet)]$ Complexes of Rh(III): Synthesis, Structure, Redox, and Spin-Spin Interaction. Inorg. Chem. 2017 56, 12764-12774.

(67) Broere, D. L. J.; Demeshko, S.; de Bruin, B.; Pidko, E. A.; Reek, J. N. H.; Siegler, M. A.; Lutz, M.; van der Vlugt, J. I. Dinuclear Palladium Complexes with Two Ligand-Centered Radicals and a Single 
Bridging Ligand: Subtle Tuning of Magnetic Properties. Chem. Eur. J. 2015, 21, 5879-5886.

(68) Broere, D. L. J.; Plessius, R.; Tory, J.; Demeshko, S.; de Bruin, B.; Siegler, M. A.; Hartl, F.; van der Vlugt, J. I. Localized MixedValence and Redox Activity within a Triazole-Bridged Dinucleating Ligand upon Coordination to Palladium. Chem. Eur. J. 2016, 22, 13965-13975.

(69) Vicente, J.; Arcas, A. Aqua Palladium Complexes: Synthesis, Properties and Applications. Coord. Chem. Rev. 2005, 249, 11351154.

(70) Bonnett, R.; Ioannou, S.; Swanson, F. J. Propentdyopents and Related Compounds. Part 4. Propentdyopent-Alkanol Adducts by the Photo-Oxygenation of Pyrromethenones. J. Chem. Soc. Perkin Trans. 1 1989, 711-714.

(71) Guibert, I.; Neibecker, D.; Tkatchenko, I. Stoicheiometric Dimerisation of Methyl Acrylate Mediated by Pd(Acac)2 $\cdot$ HBF 4 Systems and Its Relevance to the Mechanism of Catalytic Dimerisation of Acrylates $(\mathrm{Hacac}=\mathrm{MeCOCH} 2 \mathrm{COMe})$. J. Chem. Soc. Chem. Commun. 1989, 1850-1852.

(72) Dotta, P.; Kumar, P. G. A.; Pregosin, P. S.; Albinati, A.; Rizzato, S. Pd-(MOP) Chemistry: Novel Bonding Modes and Interesting Charge Distribution. Organometallics 2003, 22, 5345-5349.

(73) Wimmer, S.; Castan, P.; Wimmer, F. L.; Johnson, N. P. Preparation and Interconversion of Dimeric Di- $\mu$-Hydroxo and Tri- $\mu$-Hydroxo Complexes of Platinum(II) and Palladium(II) with 2,2' Bipyridine and 1,10-Phenanthroline. J. Chem. Soc. Dalt. Trans. 1989, No. 3, 403-412.

(74) Hagiwara, E.; Fujii, A.; Sodeoka, M. Enantioselective Addition of Enol Silyl Ethers to Imines Catalyzed by Palladium Complexes: A Novel Way to Optically Active Acylalanine Derivatives. J. Am. Chem. Soc. 1998, 120, 2474-2475.

(75) Bronner, C.; Baudron, S. A.; Hosseini, M. W.; Strassert, C. A.; Guenet, A.; De Cola, L. Dipyrrin Based Luminescent Cyclometallated Palladium and Platinum Complexes. Dalton Trans. 2010, 39, 180-184.

(76) Hall, J. D.; McLean, T. M.; Smalley, S. J.; Waterland, M. R.; Telfer, S. G. Chromophoric Dipyrrin Complexes Capable of Binding to Ti02: Synthesis, Structure and Spectroscopy. Dalton Trans. 2010, 39, 437-445.

(77) Béziau, A.; Baudron, S. A.; Fluck, A.; Hosseini, M. W. From Sequential to One-Pot Synthesis of Dipyrrin Based Grid-Type Mixed Metal-Organic Frameworks. Inorg. Chem. 2013, 52, 14439-14448.

(78) Diaz-Rodriguez, R. M.; Robertson, K. N.; Thompson, A. Classifying Donor Strengths of Dipyrrinato/Aza-Dipyrrinato Ligands. Dalton Trans. 2019, 48, 7546-7550.

(79) Lopez, G.; Ruiz, J.; Garcia, G.; Vicente, C.; Casabo, J.; Molins, E.; Miravitlles, C. Synthesis, Structural Characterization, and Reactivity toward Weak, Protic Electrophiles of Di-.Mu.Hydroxytetrakis(Pentafluorophenyl)Dipalladate(2-). Inorg. Chem. 1991, 30, 2605-2610.

(80) Pieri, G.; Pasquali, M.; Leoni, P.; Englert, U. Oxidation of Palladium(I) Dimers: Formation and X-Ray Crystal Structure of [(Me3P)2Pd( $\mu-\mathrm{OH}) 2 \mathrm{Pd}(\mathrm{PMe} 3) 2](\mathrm{CF} 3 \mathrm{SO} 3) 2$. J. Organomet. Chem. 1995, 491, 27-30.

(81) Getty, A. D.; Goldberg, K. I. Reaction of a Palladium(II) Complex Chelated by a Tridentate PNC Ligand with Water to Produce a [(PN)Pd( $\mu-\mathrm{OH})] 2$ 2+ Dimer: A Rare Observation of a WellDefined Hydrolysis of a Pd(II)-Aryl Compound. Organometallics 2001, 20, 2545-2551.

(82) Sánchez, G.; Vives, J.; López, G.; Serrano, J. L.; García, L.; Pérez, J. Exploring the Reactivity towards Acidic Protic Ligands of the Di$\mu$-Hydroxo Complex [NBu4]2[Pd2\{C4(COOMe)4\}2( $\mu-\mathrm{OH}) 2]$ : A Convenient Precursor in the Preparation of New Palladacyclopentadiene Complexes. Eur. J. Inorg. Chem. 2005, 2005, 2360-2367.

(83) Ghosh, A. Transition Metal Spin State Energetics and Noninnocent Systems: Challenges for DFT in the Bioinorganic Arena. J. Biol. Inorg. Chem. 2006, 11, 712-724.

(84) Ryeng, H.; Gonzalez, E.; Ghosh, A. DFT at Its Best: Metal- versus Ligand-Centered Reduction in Nickel Hydroporphyrins. J. Phys. Chem. B 2008, 112, 15158-15173.

(85) Conradie, J.; Brothers, P. J.; Ghosh, A. Main-Group-Element Isophlorin Complexes Revisited: The Question of a Subvalent Central Atom. Inorg. Chem. 2019, 58, 4634-4640.
(86) Alemayehu, A. B.; McCormick, L. J.; Vazquez-Lima, H.; Ghosh, A. Relativistic Effects on a Metal-Metal Bond: Osmium Corrole Dimers. Inorg. Chem. 2019, 58, 2798-2806.

(87) Foroutan-Nejad, C.; Larsen, S.; Conradie, J.; Ghosh, A. Isocorroles as Homoaromatic NIR-Absorbing Chromophores: A First Quantum Chemical Study. Sci. Rep. 2018, 8, 11952.

(88) Conradie, J.; Foroutan-Nejad, C.; Ghosh, A. Norcorrole as a Delocalized, Antiaromatic System. Sci. Rep. 2019, 9, 4852.

(89) Shaik, S.; Kumar, D.; de Visser, S. P.; Altun, A.; Thiel, W. Theoretical Perspective on the Structure and Mechanism of Cytochrome P450 Enzymes. Chem. Rev. 2005, 105, 2279-2328.

(90) Davethu, P. A.; de Visser, S. P. CO2 Reduction on an IronPorphyrin Center: A Computational Study. J. Phys. Chem. A 2019, 123, 6527-6535.

(91) Bercaw, J. E.; Durrell, A. C.; Gray, H. B.; Green, J. C.; Hazari, N.; Labinger, J. A.; Winkler, J. R. Electronic Structures of PdII Dimers. Inorg. Chem. 2010, 49, 1801-1810.

(92) Zanello, P.; Nervi, C.; Fabrizi de Biani, F. Inorganic Electrochemistry; The Royal Society of Chemistry, 2011.

(93) Robin, M. B.; Day, P. Mixed Valence Chemistry-A Survey and Classification; Emeléus, H. J., Sharpe, A. G., Eds.; Academic Press, 1968; Vol. 10.

(94) Palaniappan, V.; Singru, R. M.; Agarwala, U. C. Anionic Bridging Ligands: Thiocyanato- and Selenocyanato-Bridged Pentacyanoferrate Dimers and Their Mixed-Valence Properties. Inorg. Chem. 1988, 27, 181-187.

(95) Brunschwig, B. S.; Sutin, N. Energy Surfaces, Reorganization Energies, and Coupling Elements in Electron Transfer. Coord. Chem. Rev. 1999, 187, 233-254.

(96) Carsch, K.; Elder, S. E.; Dogutan, D. K.; Nocera, D. G.; Yang, J.; Zheng, S.-L.; Daniel, T.; Betley, T. A. Syntheses and Solid-State Structures of Two Cofacial (Bis)Dipyrrin Dichromium Complexes in Different Charge States. Acta Crystallogr. Sect. C 2021, 77, 161-166.

(97) Bonnett, R.; Buckley, D. G.; Hamzetash, D. Octaethyl-21H,24HBilin-1,19-Dione (Octaethylbilatriene-Abc). J. Chem. Soc. Perkin Trans. 1 1981, No. 0, 322-325.

(98) Hamid, M.; Zeller, M.; Hunter, A. D.; Mazhar, M.; Tahir, A. A. Redetermination of Bis(2,4-Pentanedionato)-Palladium(II). Acta Crystallogr. Sect. E 2005, 61, 2181-2183.

(99) Sheldrick, G. M. SHELXT - Integrated Space-Group and CrystalStructure Determination. Acta Crystallogr. Sect. A 2015, 71, 3-8.

(100) Dolomanov, O. V; Bourhis, L. J.; Gildea, R. J.; Howard, J. A. K.; Puschmann, H. OLEX2: A Complete Structure Solution, Refinement and Analysis Program. J. Appl. Crystallogr. 2009, 42, 339-341.

(101) te Velde, G.; Bickelhaupt, F. M.; Baerends, E. J.; Fonseca Guerra, C.; van Gisbergen, S. J. A.; Snijders, J. G.; Ziegler, T. Chemistry with ADF. J. Comput. Chem. 2001, 22, 931-967.

(102) Handy, N. C.; Cohen, A. Left-Right Correlation Energy. Mol. Phys. 2001, 99, 403-412.

(103) Lee, C.; Yang, W.; Parr, R. G. Development of the ColleSalvetti Correlation-Energy Formula into a Functional of the Electron Density. Phys. Rev. B 1988, 37, 785-789.

(104) Conradie, J.; Ghosh, A. DFT Calculations on the SpinCrossover Complex Fe(Salen)(NO): A Quest for the Best Functional. J. Phys. Chem. B 2007, 111, 12621-12624.

(105) Conradie, J.; Ghosh, A. Electronic Structure of TrigonalPlanar Transition-Metal-Imido Complexes: Spin-State Energetics, Spin-Density Profiles, and the Remarkable Performance of the OLYP Functional. J. Chem. Theory Comput. 2007, 3, 689-702.

(106) Conradie, M. M.; Conradie, J.; Ghosh, A. Capturing the Spin State Diversity of Iron(III)-Aryl Porphyrins: OLYP Is Better than TPSSh. J. Inorg. Biochem. 2011, 105, 84-91.

(107) Grimme, S.; Antony, J.; Ehrlich, S.; Krieg, H. A Consistent and Accurate Ab Initio Parametrization of Density Functional Dispersion Correction (DFT-D) for the 94 Elements H-Pu. J. Chem. Phys. 2010, 132, 154104.

(108) Astashkin, A. V; Enemark, J. H.; Raitsimring, A. 26.5-40 GHz Ka-Band Pulsed EPR Spectrometer. Concepts Magn. Reson. Part $B$ Magn. Reson. Eng. 2006, 29B, 125-136. 
For Table of Contents

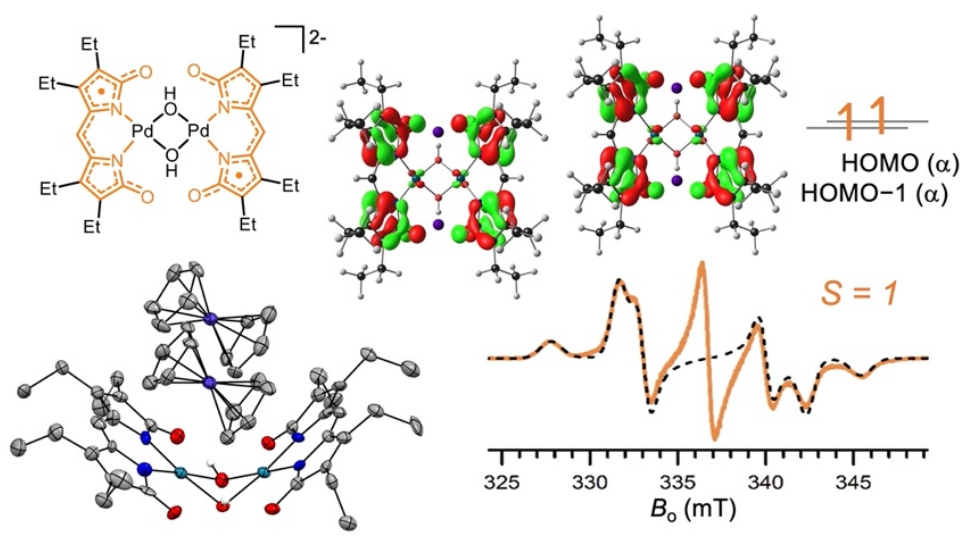

